\title{
New representation of water activity based on a single solute specific constant to parameterize the hygroscopic growth of aerosols in atmospheric models
}

\author{
S. Metzger ${ }^{1}$, B. Steil ${ }^{1}$, L. Xu ${ }^{2}$, J. E. Penner ${ }^{2}$, and J. Lelieveld ${ }^{1,3,4}$ \\ ${ }^{1}$ Max Planck Institute for Chemistry, Mainz, Germany \\ ${ }^{2}$ University of Michigan, Ann Arbor, Michigan, USA \\ ${ }^{3}$ The Cyprus Institute, Nicosia, Cyprus \\ ${ }^{4}$ King Saud University, Riyadh, Saudi Arabia
}

Correspondence to: S. Metzger (swen.metzger@mpic.de)

Received: 8 July 2011 - Published in Atmos. Chem. Phys. Discuss.: 5 September 2011

Revised: 3 June 2012 - Accepted: 4 June 2012 - Published: 22 June 2012

\begin{abstract}
Water activity is a key factor in aerosol thermodynamics and hygroscopic growth. We introduce a new representation of water activity $\left(a_{\mathrm{w}}\right)$, which is empirically related to the solute molality $\left(\mu_{\mathrm{s}}\right)$ through a single solute specific constant, $v_{i}$. Our approach is widely applicable, considers the Kelvin effect and covers ideal solutions at high relative humidity (RH), including cloud condensation nuclei (CCN) activation. It also encompasses concentrated solutions with high ionic strength at low RH such as the relative humidity of deliquescence (RHD). The constant $v_{i}$ can thus be used to parameterize the aerosol hygroscopic growth over a wide range of particle sizes, from nanometer nucleation mode to micrometer coarse mode particles. In contrast to other $a_{\mathrm{w}}{ }^{-}$ representations, our $v_{i}$ factor corrects the solute molality both linearly and in exponent form $x \cdot a^{x}$. We present four representations of our basic $a_{\mathrm{w}}$-parameterization at different levels of complexity for different $a_{\mathrm{w}}$-ranges, e.g. up to $0.95,0.98$ or 1. $v_{i}$ is constant over the selected $a_{\mathrm{w}}$-range, and in its most comprehensive form, the parameterization describes the entire $a_{\mathrm{w}}$ range $(0-1)$. In this work we focus on single solute solutions. $v_{i}$ can be pre-determined with a root-finding method from our water activity representation using an $a_{\mathrm{w}}-\mu_{\mathrm{s}}$ data pair, e.g. at solute saturation using RHD and solubility measurements. Our $a_{\mathrm{w}}$ and supersaturation (Köhler-theory) results compare well with the thermodynamic reference model E-AIM for the key compounds $\mathrm{NaCl}$ and $\left(\mathrm{NH}_{4}\right)_{2} \mathrm{SO}_{4}$ relevant for $\mathrm{CCN}$ modeling and calibration studies. Envisaged applications include regional and global atmospheric chemistry and climate modeling.
\end{abstract}

\section{Introduction}

The gas-liquid-solid partitioning of atmospheric particles and precursor gases determines to a large degree the composition and water uptake of atmospheric aerosol particles, which affect human and ecosystem health, clouds and climate (e.g. Künzli et al., 2000; IPCC, 2007). The most abundant aerosol species is water. The aerosol liquid water content (AWC) governs the size distribution, the atmospheric lifetime of both particles and interacting gases, and particle optical properties. In thermodynamic equilibrium, the AWC depends primarily on the available water vapor, ambient temperature $(T)$ and relative humidity (RH). The AWC is determined by the particle water activity $\left(a_{\mathrm{w}}\right)$ and depends on the particle hygroscopicity, i.e. the ability to absorb (release) water vapor from (to) the surrounding atmosphere. In particular the ability of salt solutes to dissolve causes hygroscopic growth (HG) of aerosol particles at subsaturated atmospheric conditions $(\mathrm{RH}<100[\%])$, where the equilibrium water uptake of atmospheric aerosols is generally limited by the available water vapor. For instance, sea salt particles can deliquesce at a very low RH of deliquescence (RHD) below 40 [\%], because they contain a small amount of the very hygroscopic salt magnesium chloride $\left(\mathrm{MgCl}_{2}\right)$. Therefore, marine air is often much hazier than continental air at the same $T$ and RH. The HG of atmospheric aerosol particles influences heterogeneous reactions, light extinction and visibility, and is important for the aerosol radiative forcing of climate (e.g. Pilinis et al., 1995). The HG and AWC often involve gas/liquid/solid aerosol partitioning that is difficult to predict

Published by Copernicus Publications on behalf of the European Geosciences Union. 
numerically, even if the complex thermodynamic system is simplified by assuming phase equilibrium (e.g. Wexler and Potukuchi, 1998; Seinfeld and Pandis, 2006).

At the microscopic level two mechanisms of water uptake are important: (i) Adsorption of water on insoluble surfaces, whereby the fraction of surface area covered by adsorbed water is proposed as a criterion for hydrophilicity (e.g. Naono and Nakuman, 1991). (ii) Absorption of water by soluble particulates, which are by definition hydrophilic. For atmospheric aerosols the absorption of water by soluble compounds is the most important, since adsorption does not contribute much to the total AWC. Soluble and in particular hygroscopic particles take up water from the atmosphere for solute hydration. An increase in solute concentration (e.g. due to condensation of volatile compounds, coagulation or chemical reactions) therefore either leads to additional water uptake, or to solute precipitation (causing a solid phase to co-exist with the aqueous phase), while a decrease of the solute concentration (e.g. due to evaporative loss or chemical reactions) is associated with the evaporation of aerosol water, so that at equilibrium the aerosol molality of a given aerosol composition remains constant for a given $T, \mathrm{RH}$ and $a_{\mathrm{w}}$.

The aerosol HG can be determined for certain solutes from laboratory $a_{\mathrm{w}}$ measurements (e.g. Tang and Munkelwitz, 1994), or calculated from Raoult's law (Raoult, 1888) if nonidealities of solution are taken into account (e.g. Warneck, 1988; Pruppacher and Klett, 2007). According to Köhlertheory (Köhler, 1936) and Raoult's law, the Raoult-term, which considers the lowering of the equilibrium vapor pressure with increasing solute concentration at a given $\mathrm{RH}$, is complemented by the Kelvin-term, which accounts for the increase in the water vapor pressure due to the curvature of the particle surface. According to the Köhler equations the equilibrium size of an aerosol droplet is determined for a given dry size, chemical composition, $\mathrm{RH}$ and $T$, by accounting for the dissolution of gases into droplets, changes in surface tension, ion charges, or density of the droplet solutions (e.g. Reiss, 1950; Young and Warren, 1992; Konopka, 1996; Shulman et al., 1996; Laaksonen et al., 1998; Charlson et al., 2001; Russell and Ming, 2002; Mikhailov et al., 2004; Biskos et al., 2006a, b; Seinfeld and Pandis, 2006; McFiggans et al., 2006; Pruppacher and Klett, 2007; Rose et al., 2008; Mikhailov et al., 2009; Ruehl et al., 2010).

Three types of methods have been used to account for hygroscopic growth of atmospheric aerosols in general circulation models (GCMs): (i) the $f(\mathrm{RH})$ method, (ii) Köhlertheory and (iii) thermodynamic equilibrium models. The $f(\mathrm{RH})$ method (Charlson et al., 1992) scales particle optical properties as a function of RH. In a simplified manner, this method accounts for the hygroscopic nature of water-soluble aerosol particles and, hence, has been used for first-order estimates of aerosol HG and the corresponding radiative forcing of climate. The second method explicitly accounts for the hygroscopic nature, since the Köhler equation is based on the Raoult-term. However, both methods do not explic- itly account for gas-liquid-solid partitioning and deliquescence that accompanies aerosol hygroscopic growth. Only models that also account for the gas-liquid-solid partitioning of single and mixed solute solutions can calculate the RHD based HG factor (HGF) of single and mixed solutions, which usually includes various inorganic, organic and non-soluble compounds.

In Sect. 2 we introduce a new representation of water activity, which provides the basis of our revised gasliquid-solid equilibrium partitioning model, i.e. version 4 of the EQuilibrium Simplified Aerosol Model (EQSAM4). EQSAM4 can be used in a GCM to calculate the mixed solution aerosol HGF of various compounds relevant to atmospheric aerosol modeling - the model is described in a companion paper (Metzger et al., 2011). Here we present four different representations of our basic $a_{\mathrm{w}}$-parameterization to accommodate different $a_{\mathrm{w}}$-ranges relevant for GCM applications. $v_{i}$ is constant for a given temperature over the $a_{\mathrm{w}}$-range, and in its most comprehensive form, the parameterizations describes the entire $a_{\mathrm{w}}$ range $(0-1) . v_{i}$ is predetermined with a root-finding method (bisection) using RHD and solubility measurements. In Sect. 3 our $a_{\mathrm{w}}$ parameterizations are applied for three cases: (a) flat surface, i.e. without Kelvin-term and sub-saturation $(\mathrm{RH}<100[\%])$, (b) curved surface, i.e. including Kelvin-term and subsaturation, and (c) supersaturation with Kelvin-term, i.e. $\mathrm{RH} \geq 100$ [\%]. The results are compared against the thermodynamic reference model E-AIM (Wexler and Clegg, 2002; Clegg and Wexler, 2007) and the $\kappa$-method of Petters and Kreidenweis (2007) for two key compounds $\mathrm{NaCl}$ and $\left(\mathrm{NH}_{4}\right)_{2} \mathrm{SO}_{4}$, which are important for modeling of cloud condensation nuclei $(\mathrm{CCN})$ and central for $\mathrm{CCN}$ calibrations (Frank et al., 2006, 2007) and CCN measurements (Dusek et al., 2006; Rose et al., 2008). We discuss our results in Sect. 4 and conclude with Sect. 5. Additional information is provided in the appendix and the Supplement. A comprehensive box model inter-comparison of major inorganic aerosol thermodynamic properties of mixed solutions predicted by EQSAM4, which applies the parameterizations presented here, and EQUISOLV II (Jacobson et al., 1996, 1999) is the subject of a separate publication.

\section{New water activity representation}

\subsection{Parameterization based on constant $v_{i}$}

Widely used representations for $a_{\mathrm{w}}$ - briefly summarized in Appendix A2 - are quite complex, since correction coefficients for non-ideality are often dependent on $a_{\mathrm{w}}$, in contrast to the underlying original methods, which were, however, restricted to the application of ideal solutions. For instance, the osmotic coefficient model (OS: Eq. A4), or the Van't Hoff factor model (VH: Eq. A5) are used with a multi parameter function of molality that is more complex than the basic 
$a_{\mathrm{w}}$ fitting function type (see e.g. Rose et al., 2008, referred to as Rose08). Only the effective hygroscopicity parameter model (EH: Eq. A7) represents $a_{\mathrm{w}}$ with a single parameter, but it should not be used for concentrated solutions. Further, the activity coefficient model (AC: Eq. A9) clearly depends on $a_{\mathrm{w}}$-dependent activity coefficients. A closer inspection of the numerics used by these methods shows that they have in common the use of one class of fitting function type that is combined with a parameter to correct the solute molality $\mu_{\mathrm{s}}$ for non-ideality, i.e. the $\mathrm{VH}$ and $\mathrm{AC}$ models use a rational function approach, whereas the OS model uses an exponential fit.

The basic idea behind our new approach is to combine two types of fitting functions for $\mu_{\mathrm{s}}$ : a rational function combined with an exponential function (see Appendix B for details).

This has been motivated by several aspects:

1. To better represent the entire water activity range.

2. To cover the range of $a_{\mathrm{w}}$ and the Köhler curve without dealing with a parameter function.

3. To derive a simpler and more robust parameter, i.e. ideally a single constant.

4. To develop a simple method to obtain the single parameter or constant.

We relate $a_{\mathrm{W}}$ and $\mu_{\mathrm{s}}$ through a dimensionless single solute specific constant, i.e. $v_{i}$, which corrects $\mu_{\mathrm{s}}$ both in a linear and an exponent form according to a functional form of $x \cdot a^{x}$, i.e.

$$
\begin{aligned}
a_{\mathrm{w}} & =\left(A+\mu_{\mathrm{s}}^{\mathrm{o}} \cdot M_{\mathrm{w}} \cdot v_{i} \cdot\left[\frac{1}{\mu_{\mathrm{s}}^{\mathrm{o}}} \cdot \mu_{\mathrm{s}}+B\right]^{v_{i}}\right)^{-1} \\
& =\left(A+\mu_{\mathrm{s}}^{\mathrm{o}} \cdot M_{\mathrm{W}} \cdot v_{i} \cdot\left[\frac{1}{\mu_{\mathrm{s}}^{\mathrm{o}}} \cdot \frac{1}{M_{\mathrm{s}} \cdot\left(1 / \chi_{\mathrm{s}}-1\right)}+B\right]^{v_{i}}\right)^{-1}
\end{aligned}
$$

$\mu_{\mathrm{s}}$ [mol(solute) $\left.\mathrm{kg}^{-1}\left(\mathrm{H}_{2} \mathrm{O}\right)\right]$ denotes the solute molality defined by Eq. (A11) and $\chi_{\mathrm{s}}^{\text {sat }}[-]$ the mass fraction. To match units with the dimensionless water activity $a_{\mathrm{w}}$, we divide $\mu_{\mathrm{s}}$ by a reference concentration of unity, $\mu_{\mathrm{s}}^{\mathrm{o}}=$ $1\left[\mathrm{~mol} \mathrm{~kg}^{-1}\right]$. Accordingly, we multiply the molar mass of water $\left.M_{\mathrm{w}}\left[\mathrm{kg} \mathrm{mol}^{-1}\right)\right]$ by $\mu_{\mathrm{s}}^{\mathrm{o}}$. $A[-]$ and $B[-]$ are dimensionless correction terms and defined in Sect. 2.2. The dimensionless constant $v_{i}$ can be pre-determined from any single $a_{\mathrm{w}}-\mu_{\mathrm{s}}$ data pair by solving Eq. (1) with a root-finding method, e.g. bisection (see Sect. 2.3). According to our findings (see Sect. 3), a constant $v_{i}$ is applicable to the entire $a_{\mathrm{w}}$-range (0-1).

\subsection{Correction terms $A$ and $B$}

As outlined in Appendix B1, the basic approach of combining two fitting function types leads to $A=1$ and $B=0$ in Eq. (1). This is applicable over the $a_{\mathrm{w}}$-range [0-0.95].
This basic solution has to be modified to cover the entire $a_{\mathrm{w}}$-range [0-1]. We introduce a form for the correction terms $A$ and $B$, which are only functions of molality, but are allowed to include the parameter $v_{i}$. The modifications in Eq. (1) should not be allowed to dominate the basic mathematical characteristics of the simplest form, i.e. $A \approx 1$ and $B \ll \mu_{\mathrm{s}}$, and have to represent the "ideal solution" limit $\left(a_{\mathrm{w}}=1\right)$. Accurate results have been achieved with the following structure of the two correction terms (see Appendix B2 for details):

$$
\begin{aligned}
& A=\left(1+v_{i} \cdot \mu_{\mathrm{s}} \cdot M_{\mathrm{w}}\right) \cdot \exp \left(-M_{\mathrm{w}} \cdot \mu_{\mathrm{s}}^{\mathrm{o}} \cdot v_{i} \cdot\left(\frac{\mu_{\mathrm{s}}}{\mu_{\mathrm{s}}^{\mathrm{o}}}\right)^{v_{i}}\right) \\
& B=\left(1+\frac{1}{v_{i} \cdot \mu_{\mathrm{s}} \cdot M_{\mathrm{s}}}\right)^{-1} \cdot\left(v_{i} \cdot \frac{\mu_{\mathrm{s}}}{\mu_{\mathrm{s}}^{\mathrm{o}}}\right)^{-\frac{1}{v_{i}}}
\end{aligned}
$$

To match units, we apply the reference molality $\mu_{\mathrm{s}}^{\mathrm{o}}=$ $1\left[\mathrm{~mol} \mathrm{~kg}^{-1}\right]$ introduced with Eq. (1). $\left.M_{\mathrm{w}}\left[\mathrm{kg} \mathrm{mol}^{-1}\right)\right]$ and $\left.M_{\mathrm{S}}\left[\mathrm{kg} \mathrm{mol}^{-1}\right)\right]$ are the molar mass of water and solute, respectively.

To reduce the dependency on $\mu_{\mathrm{s}}$, we define an alternative form for the B-term in Eq. (1) with $A=1$, which is approximately applicable to the $a_{\mathrm{w}}$-range [0-0.98] (see Sect. 3 for evaluation results):

$B_{98}=10^{\left[\frac{2}{v_{i}}-2\right]}$.

Applying Eq. (1) with Eq. (4) is straightforward and covers the RH range most important for atmospheric aerosols. It is useful for many applications, especially in GCMs in which cloud formation is often parameterized by RH thresholds below $100 \%$, thus preventing overlap between the cloud parameterization and $\mathrm{CCN}$ activation.

\subsection{Determination of $v_{i}$}

In general, $v_{i}$ can be pre-determined using any single $a_{\mathrm{w}}-\mu_{\mathrm{s}}$ data pair by solving Eq. (1) with a root-finding method, e.g. bisection. Such a data pair is readily given at saturation by the RH of deliquescence (RHD) and the saturation molality, $\mu_{\mathrm{s}}^{\mathrm{sat}}\left[\mathrm{mol} \mathrm{kg}^{-1}\right] . \mu_{\mathrm{s}}^{\mathrm{sat}}$ is related to the mass fraction $\chi_{\mathrm{s}}[-]$ by Eq. (A11) and at saturation $\chi_{\mathrm{s}}^{\text {sat }}$ equals the mass fraction solubility, $w_{\mathrm{s}}[-]$, i.e. the solute's dry mass required for saturation. Since RHD and $w_{\mathrm{s}}$ measurements are available for major compounds that are important for atmospheric aerosol chemistry, e.g. from the CRC Handbook of Chemistry and Physics (2006), we use a RHD- $w_{\mathrm{s}}$ data pair to determine $v_{i}$ from Eq. (1), which we express with the Kelvin-term $\left(K_{\mathrm{e}}\right)$ using Eq. (A1). Substitution of $a_{\mathrm{w}}=\frac{\mathrm{RH}}{K_{\mathrm{e}}}$ at the left hand side of Eq. (1) yields a relation between the solute molality and $\mathrm{RH}$, i.e.

$\mathrm{RH}=\frac{K_{\mathrm{e}}}{\left(A+\mu_{\mathrm{s}}^{\mathrm{o}} \cdot M_{\mathrm{w}} \cdot v_{i} \cdot\left[\frac{1}{\mu_{\mathrm{s}}^{\mathrm{o}}} \cdot \mu_{\mathrm{s}}+B\right]^{\nu_{i}}\right)}$ 
Table 1. Overview of the applied cases using four different water activity, $a_{\mathrm{w}}$-parameterizations.

\begin{tabular}{llllllll}
\hline Model & RH & $a_{\mathrm{w}}$ & $K_{(\mathrm{e})}$-term $^{\mathrm{a}}$ & A-term & B-term & $v_{i}$ from $^{\text {b }}$ & range $^{\mathrm{c}}$ \\
\hline Para1 & Eq. (5a) & Eq. (1) & yes & Eq. (2) & Eq. (3) & Eq. (5b) & entire RH \\
Para2 & Eq. (5a) & Eq. (1) & no & Eq. (2) & Eq. (3) & Eq. (5b) & RH 0-100 \\
Para3 & Eq. (5a) & Eq. (1) & no & $A=1$ & Eq. (4) & Eq. (5b) & RH 0-98 \\
Para4 & Eq. (5a) & Eq. (1) & no & $A=1$ & $B=0$ & Eq. (5b) & RH 0-95 \\
\hline
\end{tabular}

${ }^{a}$ Using Eq. (A1).

${ }^{\mathrm{b}} v_{i}$ has been determined for all cases with $K_{(\mathrm{e})}=1$.

${ }^{\mathrm{c}}$ Range over which the model can be applied.

At saturation, $\mathrm{RH}=\mathrm{RHD}$ and $w_{\mathrm{s}}=\chi_{\mathrm{s}}^{\text {sat }}$, and Eq. (5a) can be expressed with Eq. (A11) as:

$$
\begin{aligned}
& \mathrm{RHD}=\frac{K_{\mathrm{e}}}{\left(A+\mu_{\mathrm{s}}^{\mathrm{o}} \cdot M_{\mathrm{w}} \cdot v_{i} \cdot\left[\frac{1}{\mu_{\mathrm{s}}^{\mathrm{o}}} \cdot \mu_{\mathrm{s}}^{\mathrm{sat}}+B\right]^{v_{i}}\right)} \\
& =\frac{K_{\mathrm{e}}}{\left(A+\mu_{\mathrm{s}}^{\mathrm{o}} \cdot M_{\mathrm{w}} \cdot v_{i} \cdot\left[\frac{1}{\mu_{\mathrm{s}}^{\mathrm{o}}} \cdot \frac{1}{M_{\mathrm{S}} \cdot\left(1 / w_{\mathrm{S}}-1\right)}+B\right]^{v_{i}}\right)}
\end{aligned}
$$

$T$-dependent RHD values can be obtained from (e.g. Wexler and Potukuchi, 1998):

$\operatorname{RHD}_{\text {flat }}(T)=\mathrm{RHD}_{\text {flat }}\left(T_{\mathrm{o}}\right) \cdot \exp \left[T_{\text {coef }} \cdot\left(\frac{1}{T}-\frac{1}{T_{\mathrm{o}}}\right)\right]$

Since there are no size dependent RHD measurements available we assume:

$\mathrm{RHD}=\mathrm{RHD}_{\text {flat }} \cdot K_{\mathrm{e}}$

with RHD flat being the RHD for flat surfaces.

We determine $v_{i}$ by using temperature dependent RHD and $w_{\mathrm{s}}$ measurements, and by solving Eqs. $(5 \mathrm{~b}, \mathrm{c})$ with a root finding method (bisection), considering four different combinations of Eqs. (1-4). Table 1 summarizes the $a_{\mathrm{w}}$-models, which apply to different $a_{\mathrm{w}}$-ranges, i.e.

1. Para1: combining Eq. (1) with $A$ - Eq. (2), $B$ - Eq. (3) and the $K_{\mathrm{e}}$-term - Eq. (A1).

This is our most accurate model and applicable to curved surface and the entire $a_{\mathrm{w}}$ and $\mathrm{RH}$ range.

2. Para2: combining Eq. (1) with $A-$ Eq. (2), $B$ - Eq. (3) and $K_{\mathrm{e}}=1$.

This model assumes flat surface solutions, where $K_{\mathrm{e}}$ can be neglected. It also applies to the entire $a_{\mathrm{w}}$-range [0-1], but it is limited to bulk water activity modeling applications.

3. Para3: combining Eq. (1) with the simplified $B_{98}$-term - Eq. (4), and $A=1$ and $K_{\mathrm{e}}=1$.

This model is applicable to $\mathrm{RH} \leq 98$ [\%] and bulk modeling.

4. Para4: combining Eq. (1) with the simplest choice of $A=1, B=0$, and $K_{\mathrm{e}}=1$.
This model is applicable to $\mathrm{RH} \leq 95$ [\%] and bulk modeling.

The procedure of $v_{i}$ determination is to solve Eq. (5b) once for each model listed in Table 1 with the bisection method by using:

1. $w_{\mathrm{s}}=\chi_{\mathrm{s}}^{\text {sat }}$ to obtain $\mu_{\mathrm{s}}^{\text {sat }}$ with Eq. (A11) (same for all models of Table 1).

2. $A$ from Eq. (2), with $\mu_{\mathrm{s}}=\mu_{\mathrm{s}}^{\mathrm{sat}}$, for the models Para1 and Para2.

For the models Para 3 and Para4 we set $A=1$ for the $v_{i}$ determination.

3. $B$ from Eq. (3), with $\mu_{\mathrm{s}}=\mu_{\mathrm{s}}^{\mathrm{sat}}$, for the models Para1 and Para2.

For the model Para3 we use $B$ from Eq. (4), while for Para4 we set $B=0$.

4. The Kelvin-term is set to $K_{\mathrm{e}}=1$ for the $v_{i}$ determination for all models, since it cancels out in Eq. (5b) because of our assumption Eq. (5d).

Note that this $v_{i}$ procedure yields a unique $v_{i}$ for each model; see Appendix B3 for details. With $v_{i}$ pre-determined, one can calculate for each model and application range, listed in Table 1, the $a_{\mathrm{w}}$ from Eq. (1) and the RH from Eq. (5a) for a given $\mu_{\mathrm{s}}$. Note that $\nu_{i}$ is constant once it has been determined from Eq. (5b). The HGF can be obtained from Eq. (A2). The RHD and the derived $v_{i}$ values are listed for two reference solutes, $\mathrm{NaCl}_{(\mathrm{cr})}$ and $\left(\mathrm{NH}_{4}\right)_{2} \mathrm{SO}_{4}(\mathrm{cr})$, in Table 2 for the four parameterization models listed in Table 1. Table 3 extends the flat surface cases of Table 2, by showing size-dependent RHD values for different aerosol dry diameters, $D_{\mathrm{s}},=0.05$, $0.1,0.5,1[\mu \mathrm{m}]$, using Eq. (5d).

\section{Applications}

To evaluate the water activity $\left(a_{\mathrm{w}}\right)$ parameterization, Eq. (1), we compute the $\mathrm{RH}$ for the four cases listed in Table 1 and detailed in Sect. 2.3 from the solute molality $\mu_{\mathrm{s}}$. The aerosol hygroscopic growth factor (HGF) is calculated from 
Table 2. $v_{i}$ and RHD values at $T_{\mathrm{O}}=298.15[\mathrm{~K}]$ and $D_{\mathrm{S}}=1[\mu \mathrm{m}]$ for the four models of Table 1 .

\begin{tabular}{lccccc}
\hline Solute & $v_{i}$-Para1 & $v_{i}$-Para2 & $v_{i}$-Para3 & $v_{i}$-Para4 & RHD* \\
\hline $\mathrm{NaCl}_{(\mathrm{cr})}$ & 1.737506 & 1.737506 & 1.384214 & 1.408369 & 0.7528 \\
$\left(\mathrm{NH}_{4}\right)_{2} \mathrm{SO}_{4}(\mathrm{cr})$ & 1.661410 & 1.661410 & 1.305553 & 1.335281 & 0.7997 \\
\hline
\end{tabular}

* RHD measurements for flat surface (values of Fountoukis and Nenes, 2007).

Table 3. Estimated* RHD values for different $D_{\mathrm{s}}$.

\begin{tabular}{lccccc}
\hline$D_{\mathrm{s}}[\mu \mathrm{m}]$ & 0.05 & 0.1 & 0.5 & 1 & flat surface \\
\hline $\mathrm{NaCl}_{(\mathrm{cr})}$ & 0.7704 & 0.7616 & 0.7545 & 0.7537 & 0.7528 \\
$\left(\mathrm{NH}_{4}\right)_{2} \mathrm{SO}_{4(\mathrm{cr})}$ & 0.8238 & 0.8117 & 0.8021 & 0.8009 & 0.7997 \\
\hline
\end{tabular}

* Using Eq. (5d) with the $K_{\mathrm{e}}$-term calculated with Eqs. (A1-A2).

Eq. (A2). For consistency with Rose08, we also compare our results with the parametric calculations of E-AIM. Rose08 provided in their Supplement E-AIM $a_{\mathrm{w}}-\mu_{\mathrm{S}}$ values in the $a_{\mathrm{w}}$ range $0.97-1$, which we have connected with the E-AIM web-output, with $a_{\mathrm{w}}$ and $\mu_{\mathrm{s}}$ obtained by running the EAIM model version III (http://www.aim.env.uea.ac.uk/aim/ model $3 / \bmod 3$ rhw.php), to cover the remaining $a_{\mathrm{w}}$ range from the RHD to 0.97 by keeping the large number of the Rose 08 AIM data points above 0.97 . We also calculate with Eq. (A2) from the E-AIM $a_{\mathrm{w}}-\mu_{\mathrm{S}}$ values a reference HGF, and a reference RH from Eq. (A1). The solute molality $\mu_{\mathrm{s}}$ from the E-AIM $a_{\mathrm{w}}-\mu_{\mathrm{s}}$ reference table is used to calculate the RH with our approach. For all models we calculate the Kelvin-term from Eqs. (A1-A2) by assuming volume additivity, a constant surface tension of pure water for the solutions, $\sigma_{\mathrm{sol}}=0.076\left[\mathrm{~N} \mathrm{~m}^{-2}\right]$, and a constant pure water density of $\rho_{\mathrm{w}}=997.1\left[\mathrm{~kg} \mathrm{~m}^{-3}\right]$. For a discussion of the assumptions of volume additivity and constant $\sigma_{\mathrm{sol}}, \rho_{\mathrm{w}}$, we refer to Rose 08 , who provide a comprehensive sensitivity analysis to various parameters affecting Eq. (A1). We provide a Fortran 90 program and the E-AIM reference data in the Supplement, which can be used to reproduce our results for all models listed in Table 1.

\subsection{Bulk particles - flat surface}

We start with the simplest case of flat surface, where the Kelvin-term can be neglected for the aerosol HGF calculations, i.e. particles in the subsaturated RH regime with a sufficiently large dry diameter (geometric diameter $=$ mass equivalent diameter for a compact spherical droplet) of $D_{\mathrm{s}}=$ $1[\mu \mathrm{m}]$. For this case we assume $K_{\mathrm{e}}=1$ and $a_{\mathrm{w}}=\mathrm{RH}$. And we derive the HGF from the E-AIM $\mu_{\mathrm{s}}$ data using Eq. (A2) for all models shown, i.e. Para1-4 and E-AIM. For each parameterization model we calculate the RH from Eq. (5a) by prescribing the E-AIM $\mu_{\mathrm{s}}$ values for two key-compounds considering single solute solutions: (1) pure sodium chloride, $\mathrm{NaCl}_{(\mathrm{cr})}$, and (2) pure ammonium sulfate, $\left(\mathrm{NH}_{4}\right)_{2} \mathrm{SO}_{4(\mathrm{cr})}$.
The corresponding $v_{i}$ values are listed in Table 2. The results are compared against the E-AIM reference data, by focusing on the deliquescence branch of the hysteresis curves, i.e. considering an initially dry solute that entirely deliquesce when the RH exceeds the solute's RHD.

Figure 1 shows the HGF for the RH range, RHD $\leq \mathrm{RH}<97[\%]$, while Fig. 2 shows the complementing results for the $\mathrm{RH}$ range, $97 \leq \mathrm{RH} \leq 100[\%]$, to highlight differences in the "quasi" ideal solution range close to RH 100 [\%], where the water activity approaches unity. For the bulk applications below $\mathrm{RH} \leq 95[\%]$ shown in Fig. 1, the four cases listed in Table 1 yield similar results and agree well with the E-AIM reference. However, in the remaining $\mathrm{RH}$ range the results of the parameterization models start to disagree for Para3 and Para4: i.e. Para3, which applies the simplified B-term of Eq. (4) is close to E-AIM up to $\mathrm{RH} \approx 98[\%]$, while Para4, which is the simplest representation of Eq. (1) with $A=1, B=0$ is valid up to $\mathrm{RH} \approx 95[\%]$. Above these limits the results start to deviate noticeably from E-AIM. Only the results of Para1 and Para2 agree well with the E-AIM results close to RH 100 [\%]. According to Fig. 2, the results based on Para1 and Para2 are practically identical for the entire $\mathrm{RH}$-range, which indicates that for $D_{\mathrm{s}}=1[\mu \mathrm{m}]$ the Kelvin-effect is negligible, as expected. Though in general for high RH values near saturation and for super-saturation the Kelvin-term becomes important, so that only Paral can, and will further be used for evaluation.

\subsection{Submicron sized particles - curved surface}

In the case of submicron sized particles $\left(D_{\mathrm{s}}<1[\mu \mathrm{m}]\right)$, surface curvature becomes important for the aerosol hygroscopic growth calculations. Para1 includes the Kelvin-term, Eq. (A1), and allows to calculate the RH for submicron size particles. We focus on four different dry particle diameters $D_{\mathrm{s}}=0.05, D_{\mathrm{s}}=0.1, D_{\mathrm{s}}=0.5$ and $D_{\mathrm{s}}=1[\mu \mathrm{m}]$ using the $v_{i}$ value listed in Table 2. Figure 3 compares our parameterization results with E-AIM for the subsaturated $\mathrm{RH}$ regime with $\mathrm{RH} \leq 97$ [\%], while Fig. 4 shows again the subsequent regime, i.e. $97 \leq \mathrm{RH} \leq 100[\%]$. Note that $a_{\mathrm{w}}$ obtained with Eq. (1), or with E-AIM, does not depend on the Kelvin-term $K_{\mathrm{e}}$. Following Rose08, we plot the HGF versus $\mathrm{RH}=a_{\mathrm{w}} \cdot K_{\mathrm{e}}$ which yields a $K_{\mathrm{e}}$ dependency, but also shifts the reference RHD (of E-AIM) to a higher water activity (due to $a_{\mathrm{w}} \cdot K_{\mathrm{e}}$ ). We can reproduce this shift in RHD if the 


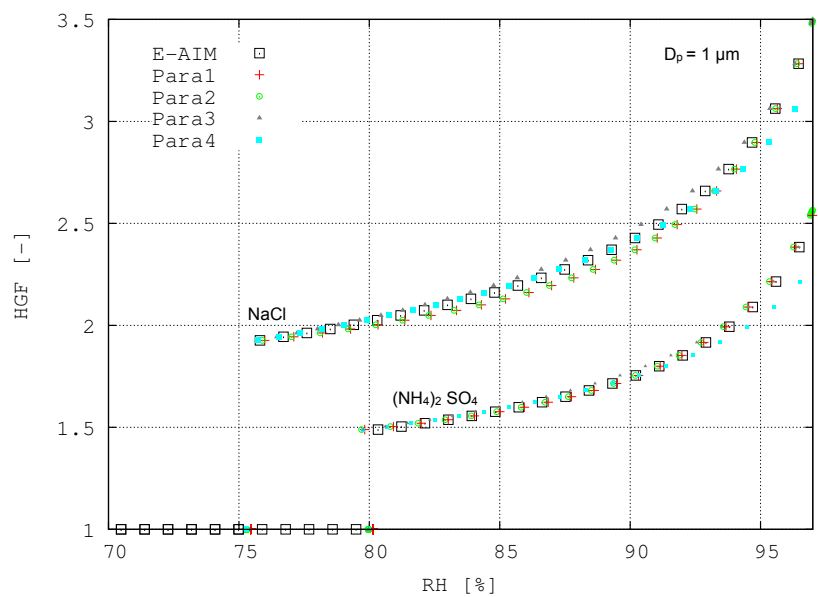

Fig. 1. Hygroscopic mass equivalent (diameter) growth factor (HGF) for pure $\mathrm{NaCl}_{(\mathrm{cr})}$ and $\left(\mathrm{NH}_{4}\right)_{2} \mathrm{SO}_{4}$ (cr) particles with a dry diameter $D_{\mathrm{S}}=1[\mu \mathrm{m}]$ for $\mathrm{RH} \leq 97[\%]$, showing the four different water activity, $a_{\mathrm{w}}$-parameterizations, summarized in Table 1 in comparison to the results of E-AIM.

Kelvin-term, Eq. (A1), is considered in the RHD calculations with Eq. (5d), and by using the pre-determined $v_{i}$ values for Para1, which are listed in Table 2 (and pre-determined for the flat-surface case with $\left.K_{(\mathrm{e})}=1\right)$. The size dependent RHD estimates are shown in Table 3 in comparison to the flat-surface values, which have been used to determine $v_{i}$ (see Sect. 2.3).

According to Figs. 3 and 4 the results of Paral agree well with those of E-AIM for different particle sizes in the subsaturated RH regime. They are also comparable to the $\kappa$ method of Petters and Kreidenweis (2007) for the ideal solution cases, but superior for concentrated solutions, in particular for $\mathrm{NaCl}$. It also appears that the results capture the decrease of the HGF for nanometer size particles reported by measurements provided by e.g. Biskos et al. (2006a, b). Note that we have not applied a shape correction factor, and used for simplicity a constant surface tension of pure water for the $K_{\mathrm{e}}$-term calculations (as mentioned above) for Para1, E-AIM and the $\kappa$-method. For a discussion of these parameters we refer to Biskos et al. (2006a, b), Rose08, Harmon et al. (2010) and Wang et al. (2010) (and references therein). In the next section we focus on the RH regime of water vapor saturation and supersaturation.

\subsection{Supersaturation - Köhler curves}

To evaluate the applicability of Eq. (1) to the upper RH limit, we compare the results obtained with Para1 and E-AIM for the case of water vapor saturation and supersaturation, i.e. $\mathrm{RH} \geq 100[\%]$. The supersaturation $S[\%]$ is defined as $S=(s-1) \cdot 100$, with $s=\mathrm{RH} / 100$. RH is obtained by solving Eq. (5a) for Para1, while we apply $\mathrm{RH}=a_{\mathrm{w}} \cdot K_{\mathrm{e}}$ for E-AIM, following Rose08. For both models we again obtain $K_{\mathrm{e}}$ from Eq. (A1), and we plot the results as a function of wet diame-

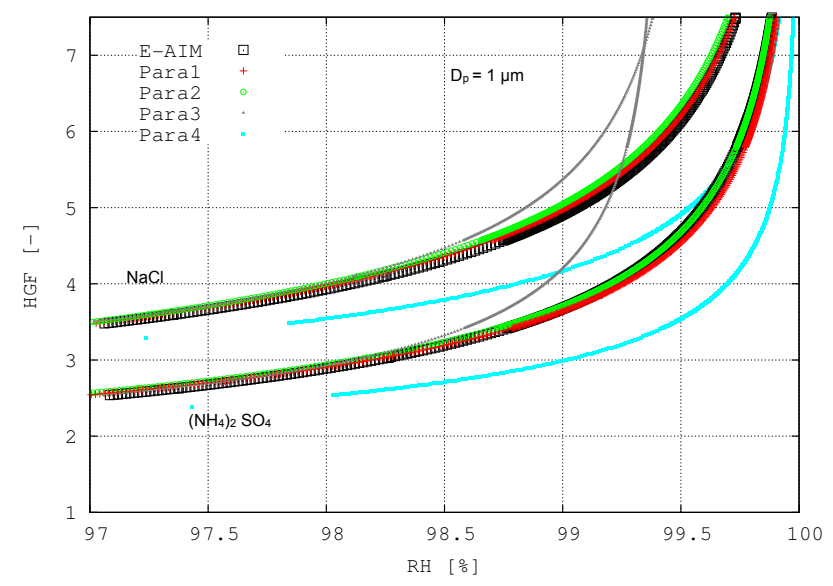

Fig. 2. Same data as Fig. 1 but for RH values within the subsaturated regime, i.e. $97 \leq \mathrm{RH} \leq 100[\%]$.

ter, $D_{\text {wet }}=D_{\mathrm{s}} \cdot \mathrm{HGF}$, with the HGF obtained from Eq. (A2) using the E-AIM reference solute molality. Figure 5, which completes the RH range of Figs. 3 and 4 for pure $\mathrm{NaCl}_{(\mathrm{cr})}$ and $\left(\mathrm{NH}_{4}\right)_{2} \mathrm{SO}_{4 \text { (cr) }}$ particles and the four dry particle diameters, i.e. $D_{\mathrm{s}}=0.05, D_{\mathrm{s}}=0.1, D_{\mathrm{s}}=0.5$ and $D_{\mathrm{s}}=1[\mu \mathrm{m}]$, shows that the results of Para1 are also comparable with those of EAIM and the $\kappa$-method for the saturated and super-saturated $\mathrm{RH}$ regimes, and therefore from the RHD to supersaturation. The results are also comparable to Fig. 15.5 of Pandis and Seinfeld (1998), which describes their approximation for ideal solutions.

Figure 6 complements Fig. 5 with results of the critical supersaturation $S_{\mathrm{c}}$, which are plotted as a function of $D_{\mathrm{s}}$. $S_{\mathrm{c}}$ is given by the maximum $S$. The results are comparable to Fig. 15.6 of Pandis and Seinfeld (1998) and Fig. 10 of Rose08. Note that our Fig. 6 covers a diameter range $5-500[\mathrm{~nm}]$, which is extended compared to Rose08 (their Fig. 10 shows $20-200[\mathrm{~nm}]$ ), so that our maximum critical supersaturation is about $10[\%]$ for $5[\mathrm{~nm}] \mathrm{NaCl}_{(\mathrm{cr})}$ particles. However, these high critical supersaturations are not our focus and merely included here to test the $v_{i}$-method. To bring the latter results closer to our artificial help lines in the loglog diagram, it was necessary to assume for the $5[\mathrm{~nm}]$ particles (and only for $5[\mathrm{~nm}]$ ) for $\mathrm{NaCl}_{(\mathrm{cr})}$ and $\left(\mathrm{NH}_{4}\right)_{2} \mathrm{SO}_{4(\mathrm{cr})}$ an estimated shape factor of 1.15 and 1.14 , respectively, which was used to correct the HGF within the Kelvin-term in Eq. (A1) for the three models shown: E-AIM, Kappa and Para1. For all other particle sizes no shape factor was applied.

\section{Discussion}

In Sect. 2, we introduced a new representation of water activity $\left(a_{\mathrm{w}}\right)$, which is empirically related to the solute molality $\left(\mu_{\mathrm{s}}\right)$ through a single solute specific constant $v_{i}$. Its main advantage is that it is straightforward to compute, e.g. less 

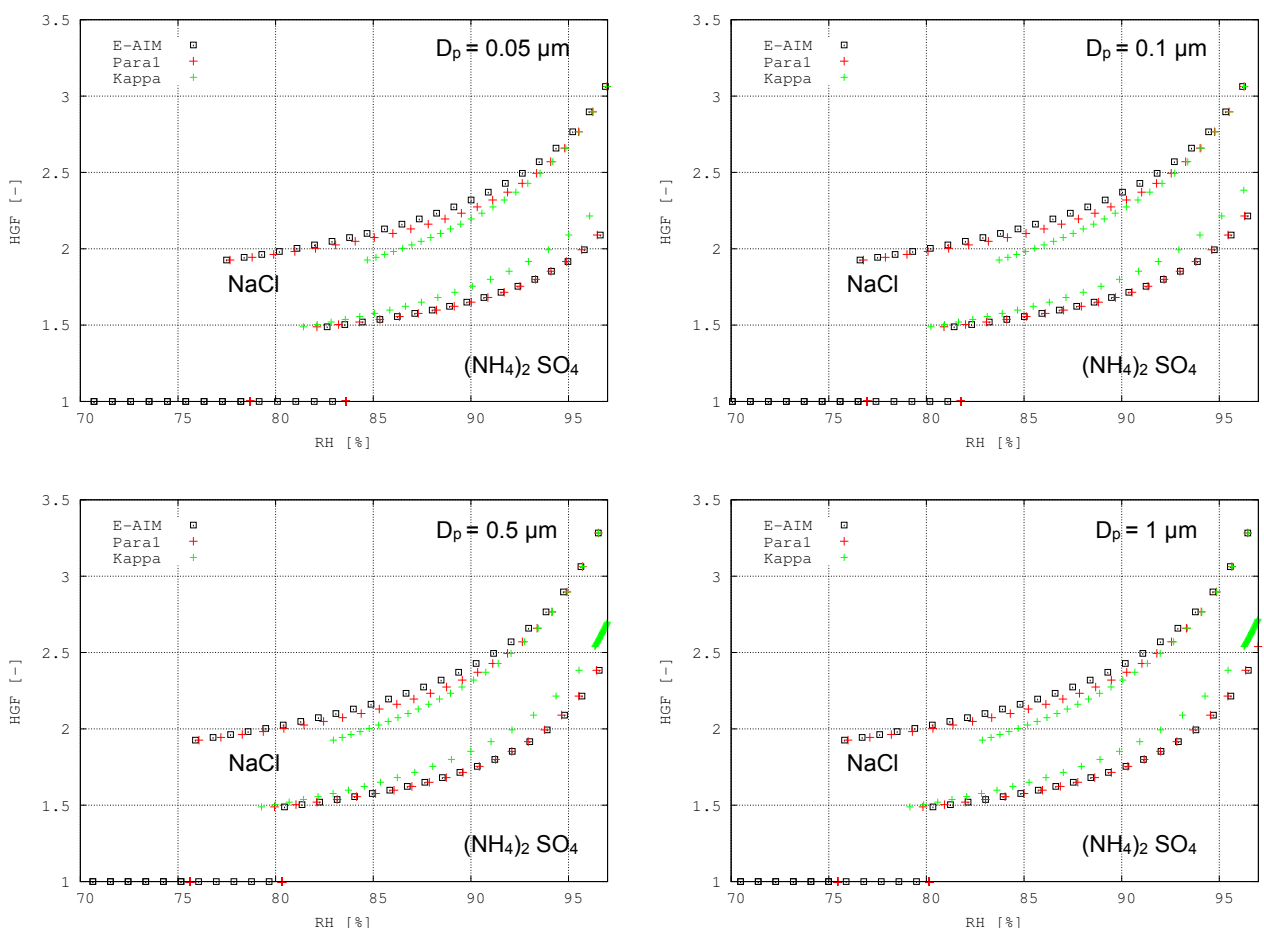

Fig. 3. Same as Fig. 1, but for dry particle diameter $D_{\mathrm{S}}=0.05$ (upper left), $D_{\mathrm{S}}=0.1$ (upper right), $D_{\mathrm{s}}=0.5$ (lower left) and $D_{\mathrm{S}}=1[\mu \mathrm{m}]$ (lower right) comparing E-AIM with Para1 of Table 1 for $\mathrm{RH} \leq 97$ [\%]. For comparison, the results using the $\kappa$ method of Petters and Kreidenweis (2007) are also included, labeled Kappa, obtained by solving Eq. (A30) of Rose08 using $\kappa=1.28$ for $\mathrm{NaCl}_{(\mathrm{cr})}$ and $\kappa=0.61$ for $\left(\mathrm{NH}_{4}\right)_{2} \mathrm{SO}_{4(\mathrm{cr})}$. Note that it is not possible to obtain HGF results below to the RHD for $\mathrm{NaCl}_{(\mathrm{cr})}$ with the $\kappa$-method using $\kappa=1.28$.
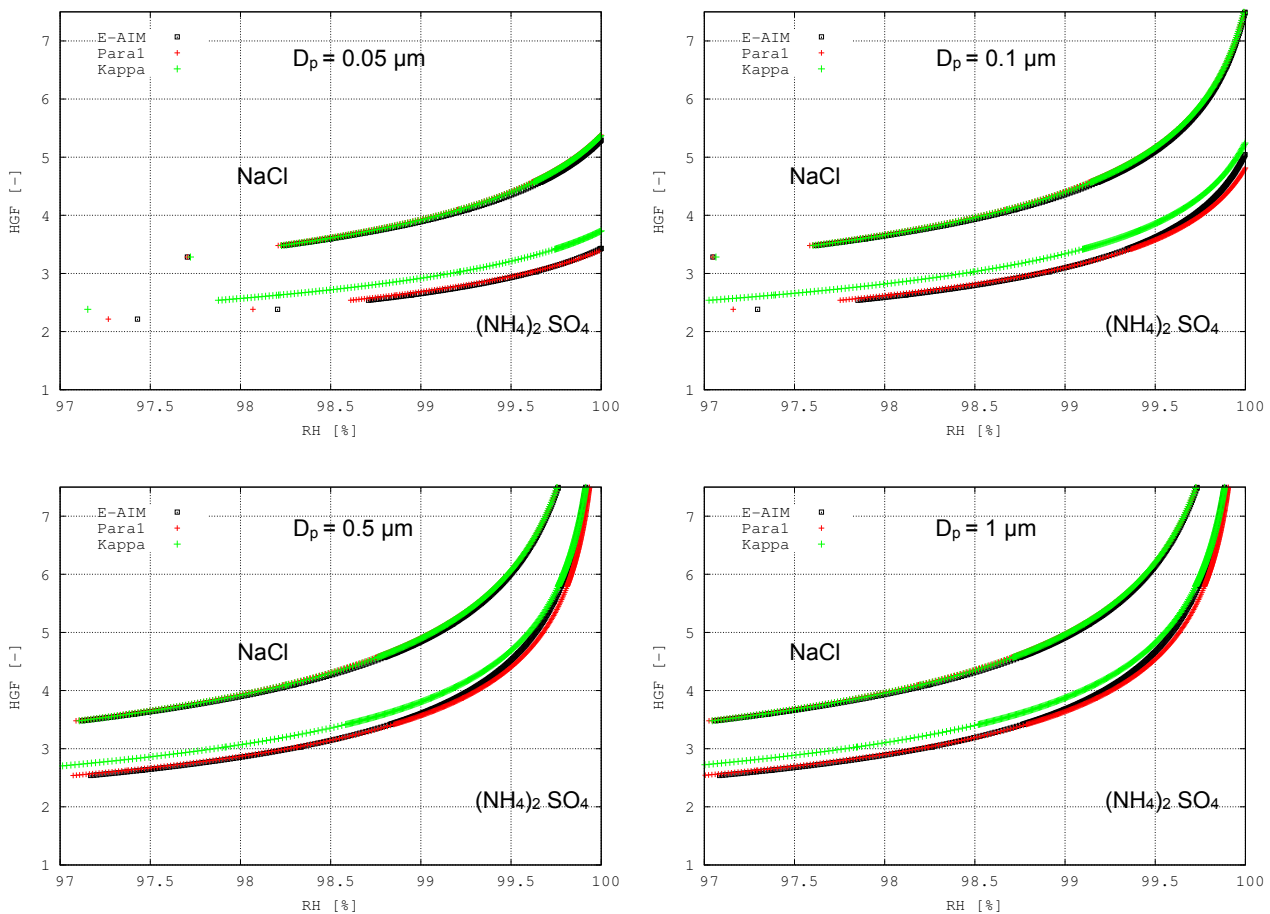

Fig. 4. Same as Fig. 3 but for high RH values within the subsaturated regime, i.e. $97 \leq \mathrm{RH} \leq 100$ [\%]. 


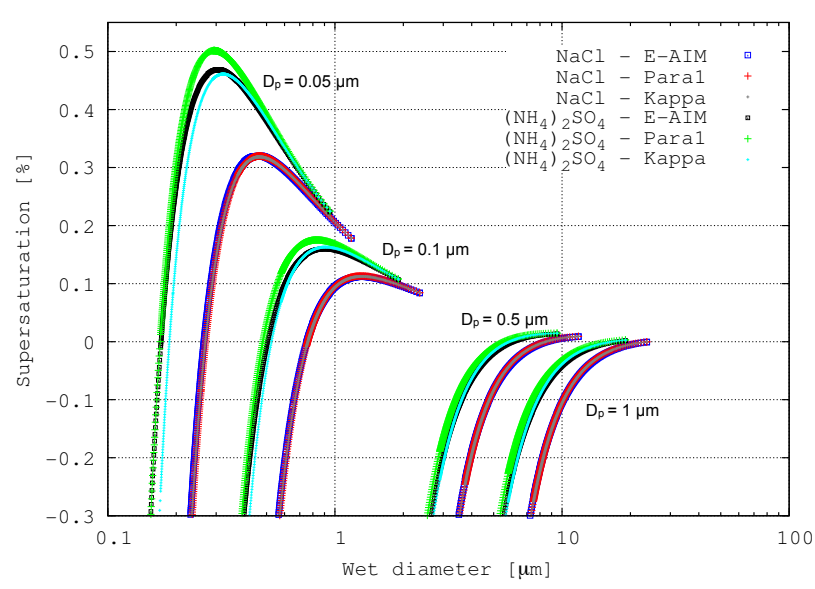

Fig. 5. Wet particle diameter, $D_{\text {wet }}$, as a function of supersaturation for pure $\mathrm{NaCl}$ and $\left(\mathrm{NH}_{4}\right)_{2} \mathrm{SO}_{4}$ aerosols with different dry diameters, i.e. $D_{\mathrm{S}}=0.05, D_{\mathrm{S}}=0.1, D_{\mathrm{S}}=0.5$ and $D_{\mathrm{S}}=1[\mu \mathrm{m}]$ as shown in Figs. 3 and 4. $S$ is defined as $S=(s-1) \cdot 100$ [\%] and $s$ is obtained from Eq. (A1) for both our results using Para1 of Table 1 and the reference calculations using the E-AIM data of Rose 08. For comparison, the results using the $\kappa$ method of Petters and Kreidenweis (2007) are also included, labeled Kappa, which are obtained by solving Eq. A30 of Rose08 using $\kappa=1.28$ for $\mathrm{NaCl}_{(\mathrm{cr})}$ and $\kappa=0.61$ for $\left(\mathrm{NH}_{4}\right)_{2} \mathrm{SO}_{4(\mathrm{cr})}$.

complicated compared to the widely used $a_{\mathrm{w}}$ methods summarized in Appendix A2. Although only a single constant is required, the $v_{i}$ based $a_{\mathrm{w}}$ representation can be used to model the $a_{\mathrm{w}}$ from the RHD until the critical supersaturation $S_{\mathrm{c}}$. This is not only unique compared to other approaches, it also allows the efficient computation of the HGF, which is important for large-scale atmospheric aerosol modeling.

\section{Simplified $a_{\mathrm{w}}$ calculations based on $v_{i}$ :}

Table 1 summarizes our different $a_{\mathrm{w}}$-models, which apply to different RH-ranges, i.e. Para1 is our most accurate parameterization model and applicable to curved surfaces and the entire atmospheric $a_{\mathrm{w}}$ and RH range, while Para2 assumes flat surface solutions, for which $K_{\mathrm{e}}$ can be neglected. It also applies to the entire $a_{\mathrm{w}^{-}}$ range [0-1], but is limited to bulk water activity modeling applications. Para3 is applicable to $\mathrm{RH} \leq 98$ [\%] and bulk modeling, while Para4 is the simplest model with $A=1, B=0$, and $K_{\mathrm{e}}=1$, and limited to $\mathrm{RH} \leq 95$ [\%] and bulk solution modeling. For this latter case, all models yield similar results and agree well with the E-AIM reference calculations. This has been shown in Sect. 3 by Figs. 1 and 2. We have further demonstrated in Sect. 3 that our results also compare well with the reference $a_{\mathrm{w}}$ calculations of E-AIM for the higher RH values and submicron sized particles (e.g. Russell and Ming, 2002; Biskos et al., 2006a, b), i.e. particles with a dry diameter $D_{\mathrm{s}}$ below $0.5[\mu \mathrm{m}]$, for which the Kelvineffect needs to be included. Our $v_{i}$-method is, in terms

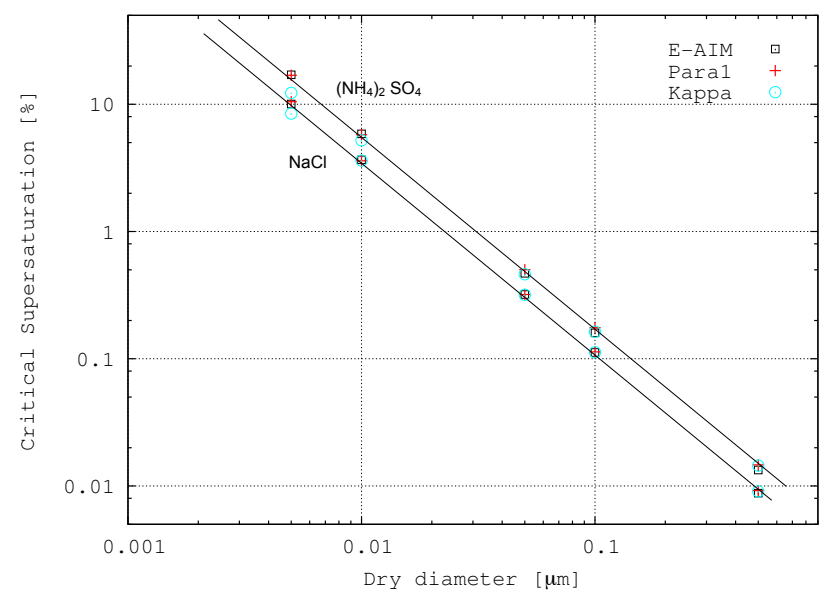

Fig. 6. Critical supersaturation as a function of dry diameter, $D_{\mathrm{s}}$, for pure $\mathrm{NaCl}$ and $\left(\mathrm{NH}_{4}\right)_{2} \mathrm{SO}_{4}$ particles with different diameters, i.e. $D_{\mathrm{s}}=0.005, D_{\mathrm{s}}=0.01, D_{\mathrm{s}}=0.05, D_{\mathrm{s}}=0.1$ and $D_{\mathrm{s}}=0.5[\mu \mathrm{m}]$, complementing Fig. 5. Note, the black solid lines are artificial help lines; the lower line and points correspond to $\mathrm{NaCl}$, the upper ones to $\left(\mathrm{NH}_{4}\right)_{2} \mathrm{SO}_{4}$.

of simplicity, comparable to the $\kappa$-method of Petters and Kreidenweis (2007), since it also is strictly a one parameter method. Both yield similar results for the ideal solution cases, though the $v_{i}$-method seems to be more accurate for concentrated solutions.

2. Advantages of the $v_{i}$ method - one constant for the entire $R H$-range:

compared to most other representations of water activity (briefly summarized in Sect. A1) our approach requires only one empirical coefficient $v_{i}$ to cover a wide range of $a_{\mathrm{w}}$ from concentrated solutions at low RH, around the compound's RHD, up to ideal solutions at large RH and $\mathrm{CCN}$ activation. The $\kappa$-method, which also requires a single parameter, is less valid for concentrated solutions as shown in Figs. 3 and 4. While for $\left(\mathrm{NH}_{4}\right)_{2} \mathrm{SO}_{4}$ particles an improved $\kappa$ parameter might be found for concentrated solutions, the $\kappa$ method can not be applied to concentrated sodium solutions without significant error. Another advantage of the $v_{i}$ method, unique for single parameter methods, is that it covers concentrated and ideal solutions of single and multiple charged ion-pairs.

3. Advantages of the $v_{i}$ method - one constant for all particle sizes:

While, the $\kappa$ method requires one coefficient per compound and particle size, the $v_{i}$ method does not, at least as long as our assumption $\mathrm{RHD}=\mathrm{RHD}_{\text {flat }} \cdot K_{\mathrm{e}}-$ given by Eqs. (5d) and (A1) - holds. Note that we have applied only one constant $v_{i}$ value for all particle sizes shown in Figs. (3-6). The $v_{i}$ values are listed in Table 2 for the two compounds. Both methods agree 


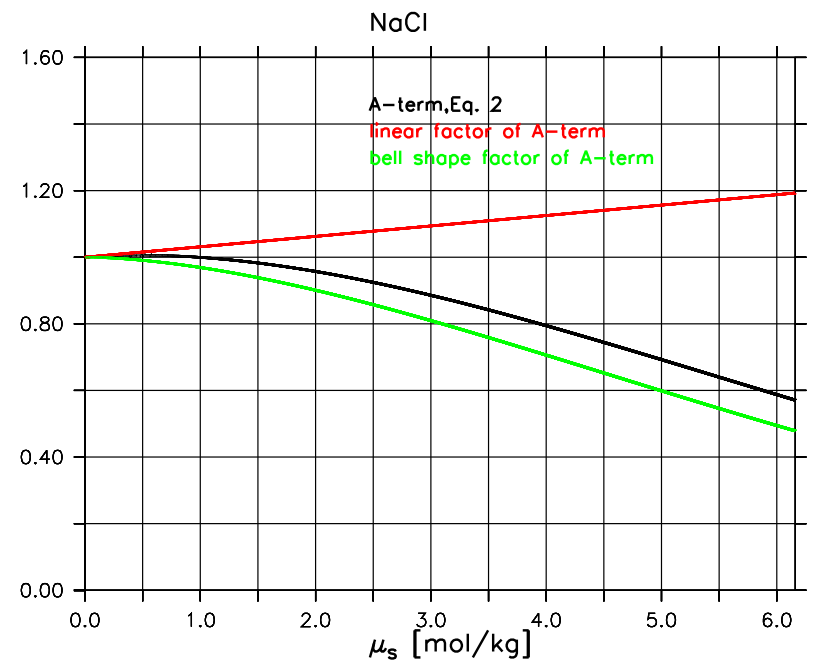

Fig. 7. A-term and its linear and bell shaped (or Gaussian) curve for $\mathrm{NaCl}$.

well w.r.t. CCN activation of the aerosols according to Köhler theory (e.g. Charlson et al., 2001; McFiggans et al., 2006) down to dry diameters $D_{\mathrm{s}}$ below $0.05[\mu \mathrm{m}]$. For $\left(\mathrm{NH}_{4}\right)_{2} \mathrm{SO}_{4}$ particles the $S_{\mathrm{c}}$ obtained from the $\kappa$ method agrees more closely with E-AIM than does the $v_{i}$ method, though the steep increase in supersaturation agrees less well with E-AIM, and at 0.005 [ $\mu \mathrm{m}]$ the $S_{\mathrm{c}}$ obtained by the $v_{i}$ method is closer to E-AIM if the same $\kappa$ and $v_{i}$ values are assumed for all particle sizes. For simplicity and clarity, we have neglected here potential effects of surface tension and other size effects, though they can be included if needed. For a discussion of this aspect we refer to Rose 08 and references therein. The uncertainty that is associated with our supersaturation calculations can be estimated from a comparison of Figs. 5 and 6 with the corresponding Fig. 10 of Rose 08. According to our Fig. 5, a relatively large difference between the $v_{i}$ method and E-AIM appears for the supersaturation for $D_{\mathrm{s}}=0.05[\mu \mathrm{m}]\left(\mathrm{NH}_{4}\right)_{2} \mathrm{SO}_{4}$ particles. In a logarithmic plot these differences are less obvious, but comparing our Fig. 6 with Fig. 10 of Rose 08 shows a smaller deviation of our method from the results of EAIM compared to the various other methods applied to compute the $S_{\mathrm{c}}$.

\section{Relation to other concepts for $a_{\mathrm{w}}$ :}

the $v_{i}$-based $a_{\mathrm{w}}$ parameterizations are related to other $a_{\mathrm{w}}$ concepts. The water activity is the central thermodynamic property from which all other properties can be derived. The various relations, which are most important for atmospheric aerosol research, are briefly summarized in the Appendix (A2). The relation of $v_{i}$ to the EQSAM3 concept of Metzger and Lelieveld (2007) is given by Para4 of Table 1. The solution of Eq. (1) for the solute molality, $\mu_{\mathrm{s}}$, corresponds to Eq. (20) in

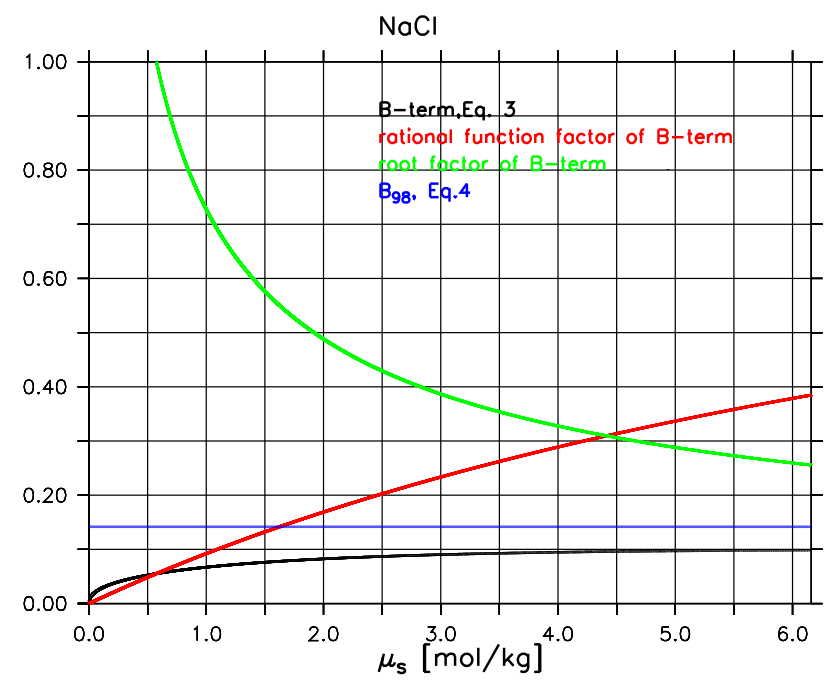

Fig. 8. B-term and its rational function and root term for $\mathrm{NaCl}$. $B_{98}$ is also plotted for comparison.

Metzger and Lelieveld (2007), with $v_{i}=v_{\mathrm{e}} / v_{\mathrm{w}}$. Both equations only depend on solute specific constants, but are limited to bulk modeling and to $\mathrm{RH} \leq 95$ [\%]. Once $v_{i}$ has been determined, Eq. (1) can be either solved for $a_{\mathrm{w}}$ or RH for a given solute molality $\mu_{\mathrm{s}}$, or for $\mu_{\mathrm{s}}$ for a given $a_{\mathrm{w}}$ or RH. For a given $\mu_{\mathrm{s}}$, Eq. (1) can be non-iteratively solved for $a_{\mathrm{w}}$ or RH for all parameterization models listed in Table 1. When the RH is prescribed, which is customary for GCM modeling applications, the hygroscopic growth factor (HGF), the saturation $(s)$ and supersaturation $(S)$ can be easily obtained from Eqs. (A1-A2), by using $\mu_{\mathrm{s}}$ from Eq. (1). Equation (1) can be solved for the solute molality for each parameterization model listed in Table 1. For Para3 and 4 the solution is straightforward, and $\mu_{\mathrm{s}}$ can be analytically calculated for a given RH. For Para 1 and 2 the dependency of the $A-, B$ - and $K_{\mathrm{e}}$-terms on $\mu_{\mathrm{s}}$, however, requires that Eq. (1) is iteratively solved using a root finding method (e.g. bisection). For GCM applications this is not a limitation, since Para3 can be used to determine $\mu_{\mathrm{s}}$ up to $\mathrm{RH} \approx 98[\%]$, which encompasses all relevant conditions (i.e. the cloud formation process is parameterized independently). For supersaturation or CCN activation studies $\mu_{\mathrm{s}}$ can be pre-calculated with Para1 for the remaining RH range, and the $\mu_{\mathrm{s}}$ values stored in look-up tables. Although this is true also for $\mu_{\mathrm{s}}$ values from other models or measurements, our parameterizations have the advantage that $\mu_{\mathrm{s}}$ can be more easily determined for compounds for which measurements or reference data are not or incompletely available for the RH range of interest. Finally, the $v_{i}$-method allows to efficiently solve mixed solution properties. 


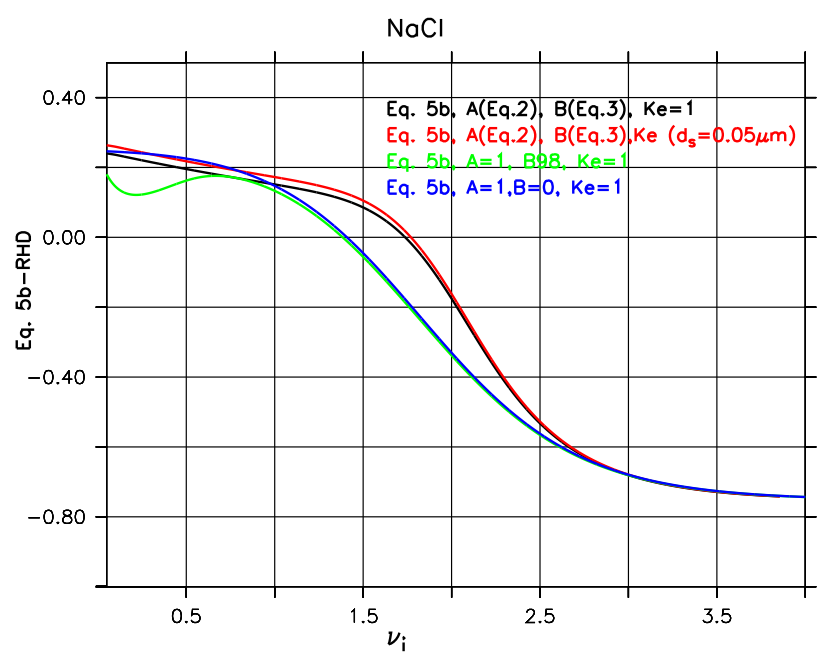

Fig. 9. $v_{i}$ values for $\mathrm{NaCl}$, satisfying "Eq. (5b)-RHD" using a rootfinding algorithm.

\section{From single to mixed solute solutions:}

our application examples shown in Figs. 1-6 focus on single solute solutions. The $v_{i}$-method can additionally be applied to mixed solutions, which has some advantages (Metzger et al., 2011). For instance, it can be efficiently combined with the widely used additive approach of partial water masses of single solutes in mixed solutions (ZSR-relation; Zdanovskii, 1948; Stokes and Robinson, 1966), or other approaches, e.g. CSB (Clegg et al., 2001; Hanford et al., 2008), compared to e.g. the water activity coefficient (AC) model, Eq. (A9). The AC model, which is the only other $a_{\mathrm{w}}$ model applied in GCMs that explicitly includes aerosol thermodynamics, requires the calculation of mixed solution activities for the entire $a_{\mathrm{w}}$-range, both with multicomponent iterations and by using a numerical solver (e.g. an iterative root finding method) to solve the activity equation of each compound. In contrast, the $v_{i}$ approach can simplify multi-component solutions, since the right hand side of Eq. (1) does not depend on the aerosol liquid water content (AW). Under the assumption of thermodynamic equilibrium, AW can be directly, i.e. non-iteratively determined with the $v_{i}$ method for a given $\mathrm{RH}$ and single solute concentration, $n_{\mathrm{s}}$, from $\mathrm{AW}\left[\mathrm{kg}\left(\mathrm{H}_{2} \mathrm{O}\right) / \mathrm{m}^{3}\right.$ (air) $]=n_{\mathrm{s}}\left[\mathrm{mol} / \mathrm{m}^{3}(\right.$ air $\left.)\right] / \mu_{\mathrm{s}}$ $\left[\mathrm{mol} / \mathrm{kg}\left(\mathrm{H}_{2} \mathrm{O}\right)\right]$. By applying the ZSR-relation, the mixed solution AW is simply the sum of its single solute solutions. Once the mixed solution AW is known, all mixed solution properties can be determined.

Using the additional approach of ranking the compounds in mixed solutions with respect their solubility, i.e. considering the salting-out effect of precipitating ion-pairs, we can construct, e.g. using Para3 (Table 1), a gas-liquid-solid partitioning model that solves the

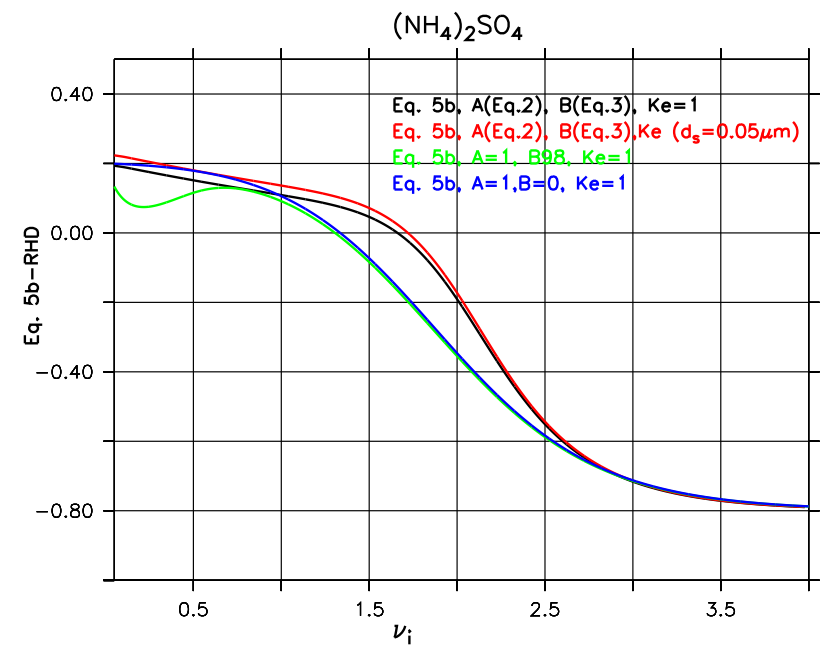

Fig. 10. $v_{i}$ values for $\left(\mathrm{NH}_{4}\right)_{2} \mathrm{SO}_{4}$, satisfying “Eq. (5b)-RHD” using a root-finding algorithm.

multi-component solutions without iterations. This has been realized with EQSAM - single and mixed solution results compared with reference calculations by EAIM and other thermodynamic models (Metzger et al. 2011; Xu, 2011). Thus, all information required to calculate the thermodynamic state of atmospheric aerosol particles is contained in a single solute specific coefficient. This has important implications for GCM applications, as the mixed solution water content and the corresponding HGF can be calculated much faster up to $\mathrm{RH} \approx 98[\%]$. Even for conditions where the Kelvinterm is needed, i.e. when Paral has to be used, the $v_{i}$ based equations speed up the mixed solution calculations, because multidimensional iterations would otherwise be requited to solve the Köhler equation, for example, when the AW dependent iterative AC method is used.

\section{Conclusions}

We have introduced a new water activity $\left(a_{\mathrm{w}}\right)$ parameterization, which requires one solute specific constant, $v_{i}$. The $v_{i}$ method is related to various other $a_{\mathrm{w}}$ representations through the relations presented in Sect. A2. In this work we have focused on single solute solutions for which $v_{i}$ has been empirically determined from RHD and solubility measurements. The key advantage of the $v_{i}$ concept for atmospheric applications is that it requires only a single constant to represent the water activity by Eq. (1), or the solute molality by the inverted Eq. (1), for the entire range of $a_{\mathrm{w}}$, while other concepts typically require solution dependent coefficients. The most accurate version of our $v_{i}$ based $a_{\mathrm{w}}$ parameterization applies to deliquesced nanometer sized particles and 
also covers cloud condensation nuclei $(\mathrm{CCN})$. Furthermore, we have derived simplified parameterizations for the efficient computation of aerosol hygroscopic growth up to relative humidities of 95 and 98 [\%]. The validity of our approach has been corroborated for $\mathrm{NaCl}_{(\mathrm{cr})}$ and $\left(\mathrm{NH}_{4}\right)_{2} \mathrm{SO}_{4(\mathrm{cr})}$ by comparing with results of the reference model E-AIM.

\section{Appendix A}

\section{A1 Köhler theory and models}

Köhler theory relates the particle growth of a spherical droplet formed on a soluble particle to the ambient relative humidity (RH), which can be expressed as (e.g. Pruppacher and Klett, 2007; Seinfeld and Pandis, 2006; Mikhailov et al., 2004, 2009; Rose et al., 2008):

$$
\begin{aligned}
& \mathrm{RH}=\frac{p_{\mathrm{w}(\mathrm{g})}}{p_{\mathrm{w}(\mathrm{g})}^{\mathrm{sa}}} \\
& =a_{\mathrm{w}} \cdot K_{\mathrm{e}} \\
& =a_{\mathrm{w}} \cdot \exp \left(\frac{4 \cdot M_{\mathrm{w}} \cdot \sigma_{\mathrm{sol}}}{R \cdot T \cdot \rho_{\mathrm{w}} \cdot D_{\mathrm{wet}}}\right) \\
& =a_{\mathrm{w}} \cdot \exp \left(\frac{4 \cdot M_{\mathrm{w}} \cdot \sigma_{\mathrm{sol}}}{R \cdot T \cdot \rho_{\mathrm{w}} \cdot g_{\mathrm{s}} \cdot D_{\mathrm{s}}}\right)
\end{aligned}
$$

$p_{\mathrm{w}(\mathrm{g})}[\mathrm{Pa}]$ and $p_{\mathrm{w}(\mathrm{g})}^{\mathrm{sat}}[\mathrm{Pa}]$ denote the partial pressures of water vapor of the ambient air at temperature $T[\mathrm{~K}]$ and at saturation at the same $T$. It is common to express the dimensionless fractional relative humidity $\mathrm{RH}[-]$ as the saturation ratio $s=\mathrm{RH}[-]$, with RH (not in italics) in [\%]. In case of supersaturation, $\mathrm{RH}>100[\%]$, it is customary to use the supersaturation $S$, which is defined as $S=(s-1) \cdot 100$ [\%].

The dimensionless term $a_{\mathrm{w}}[-]$ is the water activity of the solution (droplet) and is referred to as the volume term, since it accounts for an increase of the droplet volume $\left(D_{\text {wet }}^{3}\right)$ with increasing RH with a $1 / D_{\text {wet }}^{3}$ proportionality. $K_{\mathrm{e}}[-]$ is the Kelvin term, which accounts for a compensating effect with a $1 / D_{\text {wet }}$ proportionality and the $\mathrm{RH}$ dependent surface tension $\sigma_{\text {sol }}\left[\mathrm{J} \mathrm{m}^{-2}\right]$ of the solution droplet; $R\left[\mathrm{~J} \mathrm{~mol}^{-1} \mathrm{~K}^{-1}\right]$ is the ideal gas constant and $T[\mathrm{~K}]$ the droplet temperature, $D_{\text {wet }}$ $[\mathrm{m}]$ is the ambient droplet diameter (geometric diameter $=$ mass equivalent diameter of a compact spherical droplet). With the assumption of "volume-additivity", i.e. the volume of the solution droplet is given by the sum of the volumes of the dry solute and of the pure water contained in the droplet, $D_{\text {wet }}$ can be expressed in terms of the dry mass equivalent diameter $D_{\mathrm{S}}[\mathrm{m}]$ and the $\mathrm{RH}$ dependent mass equivalent growth factor $g_{\mathrm{s}}[-]$ of the droplet. $g_{\mathrm{s}}$ is defined as the ratio of wet to dry droplet diameter, and can be expressed in terms of the solute molality $\mu_{\mathrm{s}}=n_{\mathrm{s}} / m_{\mathrm{w}}\left[\mathrm{mol}(\right.$ solute $\left.) \mathrm{kg}^{-1}\left(\mathrm{H}_{2} \mathrm{O}\right)\right]$ :

$$
\begin{aligned}
& g_{\mathrm{s}}=\frac{D_{\mathrm{wet}}}{D_{\mathrm{s}}} \\
& =\left(\frac{V_{\mathrm{wet}}}{V_{\mathrm{s}}}\right)^{1 / 3}=\left(\frac{V_{\mathrm{w}}+V_{\mathrm{s}}}{V_{\mathrm{s}}}\right)^{1 / 3}=\left(\frac{V_{\mathrm{w}}}{V_{\mathrm{s}}}+1\right)^{1 / 3}=\left(\frac{\rho_{\mathrm{s}} \cdot m_{\mathrm{w}}}{\rho_{\mathrm{w}} \cdot m_{\mathrm{s}}}+1\right)^{1 / 3} \\
& =\left(\frac{\rho_{\mathrm{s}}}{M_{\mathrm{s}} \cdot \rho_{\mathrm{w}} \cdot \mu_{\mathrm{s}}}+1\right)^{1 / 3}
\end{aligned}
$$

$V_{\text {wet }}=V_{\mathrm{w}}+V_{\mathrm{s}}\left[\mathrm{m}^{3}\right]$ is the total volume of the wet droplet with $V_{\mathrm{s}}=m_{\mathrm{s}} / \rho_{\mathrm{s}}=n_{\mathrm{s}} M_{\mathrm{s}} / \rho_{\mathrm{s}}$ and $V_{\mathrm{w}}=m_{\mathrm{w}} / \rho_{\mathrm{w}}=$ $n_{\mathrm{w}} M_{\mathrm{w}} / \rho_{\mathrm{w}}\left[\mathrm{m}^{3}\right]$, i.e. the volumes of the initially dry solute and the associated pure water, respectively. $m_{\mathrm{S}}$ and $m_{\mathrm{w}}[\mathrm{kg}]$ denote the corresponding solute and water masses, $M_{\mathrm{s}}$ and $M_{\mathrm{W}}\left[\mathrm{kg} \mathrm{mol}^{-1}\right]$ the molar masses, $n_{\mathrm{s}}$ and $n_{\mathrm{w}}[\mathrm{mol}]$ the number of moles, and $\rho_{\mathrm{s}}$ and $\rho_{\mathrm{w}}\left[\mathrm{kg} \mathrm{m}^{-3}\right]$ the densities, respectively. Throughout this work $g_{\mathrm{s}}$ is referred to as the hygroscopic growth factor (HGF) and applied to atmospheric aerosols.

\section{A2 Water activity representations - concepts}

To clarify similarities and differences with previous work, we follow Rose et al. (2008) - abbreviated as Rose08 (available at http://www.atmos-chem-phys.net/8/1153/2008/) - as they present a comprehensive overview of water activity representations on which the various present-day Köhler models are based. Rose08 have subdivided the water activity representations into 5 categories (similar to their Table 3), i.e.

1. Activity parameterization (AP) models, e.g. Tang and Munkelwitz (1994), Tang (1996), Kreidenweis et al. (2005), which are of the type:

$a_{\mathrm{w}}=1+\sum_{q} a_{q} \cdot\left(100 \cdot \chi_{\mathrm{s}}\right)^{q}$

Tang and Munkelwitz (1994) and Tang (1996) have presented parameterizations for the activity of water in aqueous solutions derived from electrodynamic balance (EDB) single particle experiments as polynomial fit functions of $\mathrm{RH}$ dependent solute mass percentage $\left(100 \cdot \chi_{\mathrm{s}}\right)$. The solute mass fraction $\chi_{\mathrm{s}}$ and the polynomial coefficients $a_{q}$ [-] are listed e.g. in Table A2 of Rose 08 to which we refer for a further discussion.

2. Osmotic coefficient (OS) models, e.g. Robinson and Stokes (1959, 1965), Pitzer and Mayorga (1973), Brechtel and Kreidenweis (2000), which are of the type:

$$
a_{\mathrm{w}}=\exp \left(-M_{\mathrm{w}} \cdot \Phi_{\mathrm{w}} \cdot \sum_{i} \mu_{i}\right)=\exp \left(-M_{\mathrm{w}} \cdot \Phi_{\mathrm{s}} \cdot v_{\mathrm{s}} \cdot \mu_{\mathrm{s}}\right)
$$


Table A1. List of greek symbols.

\begin{tabular}{lll}
\hline Greek Symbol & Name & Unit \\
\hline$v_{i}$ & solute specific constant (introduced with Eq. (1) by this work) & {$[-]$} \\
\hline$\nu_{\mathrm{S}}$ & stoichiometric coefficient of solute ( \pm ion-pair) & {$[-]$} \\
$\gamma_{i}$ & molal-based coefficients & {$\left[\mathrm{kg}\left(\mathrm{H}_{2} \mathrm{O}\right)\right] \mathrm{mol}^{-1}$} \\
$\mu_{\mathrm{S}}$ & molality of solute & {$\left[\mathrm{mol} \mathrm{kg}^{-1}\left(\mathrm{H}_{2} \mathrm{O}\right)\right]$} \\
$\mu_{\mathrm{s}}^{\mathrm{O}}$ & reference molality of 1 mole of solute (considering stoichiometry) & {$\left[\mathrm{mol} \mathrm{kg}^{-1}\left(\mathrm{H}_{2} \mathrm{O}\right)\right]$} \\
$\mu_{\mathrm{S}}^{\text {sat }}$ & saturation molality of solute & {$\left[\mathrm{mol} \mathrm{kg}^{-1}\left(\mathrm{H}_{2} \mathrm{O}\right)\right]$} \\
$\sum_{i} \mu_{i}$ & summation over all solute molalities & {$\left[\mathrm{mol} \mathrm{kg}^{-1}\left(\mathrm{H}_{2} \mathrm{O}\right)\right]$} \\
$\Phi_{\mathrm{S}}$ & molal or practical osmotic coefficient of solute & {$[-]$} \\
$\Phi_{\mathrm{W}}$ & molal or practical osmotic coefficient of water & {$[-]$} \\
$\rho_{\mathrm{S}}$ & density of solute & {$\left[\mathrm{kg} \mathrm{m}^{-3}\right]$} \\
$\rho_{\mathrm{W}}$ & density of water & {$\left[\mathrm{kg} \mathrm{m}^{-3}\right]$} \\
$\sigma_{\mathrm{sol}}$ & surface tension of the solution droplet & {$\left[\mathrm{J} \mathrm{m}^{-2}\right]$} \\
$\chi_{\mathrm{s}}$ & solute mass fraction, referring to the solute's dry mass & {$[-]$} \\
$\chi_{\mathrm{S}}^{\text {sat }}$ & solute mass fraction, referring to the solute's dry mass at saturation & {$[-]$} \\
\hline
\end{tabular}

Table A2. List of symbols.

\begin{tabular}{|c|c|c|}
\hline Symbol & Name & Unit \\
\hline$A$ & A-term, Eq. (2) and introduced with Eq. (1) & {$[-]$} \\
\hline$B$ & B-term, Eq. (3-4) and introduced with Eq. (1) & {$[-]$} \\
\hline$a_{\mathrm{W}}$ & water activity (Raoult-term) & {$[-]$} \\
\hline$D_{\mathrm{S}}$ & dry droplet diameter of the solute & {$[\mathrm{m}]$} \\
\hline$D_{\text {wet }}$ & wet droplet diameter of the solution & {$[\mathrm{m}]$} \\
\hline$f_{\mathrm{W}}$ & rational or mole fraction scale activity coefficient of water & {$[-]$} \\
\hline$g_{\mathrm{s}}$ & hygroscopic mass equivalent (diameter) growth factor & {$[-]$} \\
\hline$i_{\mathrm{S}}$ & van't Hoff factor of solute & {$[-]$} \\
\hline$K_{\mathrm{e}}$ & surface or Kelvin-term of the solution & {$[-]$} \\
\hline$m_{\mathrm{S}}$ & crystalline mass of solute & {$[\mathrm{kg}]$} \\
\hline$m_{\mathrm{W}}$ & aqueous mass of water (solvent) & {$[\mathrm{kg}]$} \\
\hline$M_{\mathrm{S}}$ & molar mass of solute & {$\left[\mathrm{kg} \mathrm{mol}^{-1}\right]$} \\
\hline$M_{\mathrm{W}}$ & molar mass of water & {$\left[\mathrm{kg} \mathrm{mol}^{-1}\right]$} \\
\hline$n_{\mathrm{S}}$ & moles of solute & [mol] \\
\hline$\sum_{i} n_{s, i}$ & summation over all moles of solutes & {$[\mathrm{mol}]$} \\
\hline$n_{\mathrm{W}}$ & moles of water & {$[\mathrm{mol}]$} \\
\hline$p_{\mathrm{w}(\mathrm{g})}$ & water vapor & {$[\mathrm{Pa}]$} \\
\hline$p_{\mathrm{W}(\mathrm{g})}^{\mathrm{sat}}$ & vapor pressure at saturation (at given $\mathrm{T}$ ) & {$[\mathrm{Pa}]$} \\
\hline $\mathrm{RH}$ & relative humidity in percent (as used in text) & {$[\%]$} \\
\hline RH & fractional relative humidity (as used in equations) & {$[-]$} \\
\hline$s$ & saturation ratio & {$[-]$} \\
\hline$S$ & supersaturation & {$[-]$} \\
\hline$S_{\mathrm{c}}$ & critical supersaturation in percent & {$[\%]$} \\
\hline$T_{\text {coef }}$ & dimensionless temperature coefficients for the RHD & {$[-]$} \\
\hline$T_{\mathrm{O}}$ & reference temperature in Kelvin & {$[298.15 \mathrm{~K}]$} \\
\hline$T$ & temperature in Kelvin & {$[\mathrm{K}]$} \\
\hline $\mathrm{T}$ & temperature in degree Celsius & {$\left[{ }^{\circ} \mathrm{C}\right]$} \\
\hline$w_{\mathrm{s}}$ & mass fraction solubility, referring to the solute's dry mass required for saturation & {$[-]$} \\
\hline$x_{\mathrm{S}}$ & mole fraction of solute & {$[-]$} \\
\hline$x_{\mathrm{W}}$ & mole fraction of water & {$[-]$} \\
\hline
\end{tabular}


Table A3. List of names and abbreviations.

\begin{tabular}{ll}
\hline Abbreviation & Name \\
\hline sat & superscript, indicator for saturation \\
(cr) & $\begin{array}{l}\text { subscript, phase indicator for anhydrous (solid=crystalline=cr) phase } \\
\text { subscript, phase indicator for aqueous phase }\end{array}$ \\
(g) & subscript, phase indicator for gas phase \\
\hline AWC & Aerosol liquid Water Content \\
EQSAM4 & EQuilibrium Simplified Aerosol Model, version 4 \\
EMAC & ECHAM MESSy Atmospheric Chemistry-climate model \\
$f($ RH) & f(RH) method (Charlson et al., 1992) \\
GCMs & General Circulation Models \\
HG & Hygroscopic Growth \\
HGF & hygroscopic Growth Factor \\
H-TDMA & Hygroscopicity tandem differential mobility analyzer \\
IPCC & Intergovernmental Panel on Climate Change \\
$\log 10$ & decadal logarithm \\
$\log$ & natural logarithm \\
RH & Relative Humidity \\
RHD & Relative Humidity of Deliquescence \\
UNIFAC & Universal functional group activity coefficient model (Fredenslund et al., 1975) \\
ZSR-relation & Zdanovskii-Stokes-Robinson mixing rule (Zdanovskii, 1948; Stokes and Robinson, 1966) \\
\hline
\end{tabular}

According to Robinson and Stokes (1959) (the book pages are online freely accessable at http://books. google.de/books?id=6ZVkqm-J9GkC\&printsec $=$ frontcover) the water activity $a_{\mathrm{w}}$ is related to the total molality of all solute species $\sum_{i} \mu_{i}$ by the dimensionless molal osmotic coefficient of the aqueous phase $\Phi_{\mathrm{w}}[-]$, where $\sum_{i} \mu_{i}$ can be expressed as $\nu_{\mathrm{s}} \cdot \mu_{\mathrm{s}}$ if the molal osmotic coefficient of the solute $\Phi_{\mathrm{s}}$ is used in conjunction with the solute molality $\mu_{\mathrm{s}}\left[\mathrm{mol} \mathrm{kg}^{-1}\left(\mathrm{H}_{2} \mathrm{O}\right)\right]$ and the solute's stoichiometric coefficient $v_{\mathrm{s}}$. $M_{\mathrm{w}}$ is the molar mass of water in SI-units $\left[\mathrm{kg} \mathrm{mol}^{-1}\right] . \Phi_{\mathrm{w}}$ deviates from unity as the solution becomes non-ideal.

3. Van't Hoff factor (VH) models, e.g. van't Hoff (1887), Low (1969), Young and Warren (1992), which are of the type:

$a_{\mathrm{w}}=\frac{1}{1+i_{\mathrm{s}} \cdot n_{\mathrm{s}} / n_{\mathrm{w}}}=\left(1+M_{\mathrm{w}} \cdot i_{\mathrm{s}} \cdot \mu_{\mathrm{s}}\right)^{-1}$

The van't Hoff factor $i_{\mathrm{s}}[-]$, originally a constant and similar to the stoichiometric coefficient (dissociation number) $v_{\mathrm{s}}$. Nowadays, the van't Hoff-factor is applied as a function of molality, e.g. a second order polynomial with three parameters (see Rose et al., 2008 for an overview). Deviations of $i_{\mathrm{s}}$ from $v_{\mathrm{s}}$ can be attributed to solution non-idealities. The relation between $i_{\mathrm{s}}, v_{\mathrm{s}}$ and $\Phi_{\mathrm{S}}$ can be approximated by a series expansion of the exponential term in Eq. (A4) and can be approximated as (Kreidenweis et al., 2005):

$$
i_{\mathrm{s}} \approx v_{\mathrm{s}} \cdot \Phi_{\mathrm{s}}
$$

4. Effective hygrosocopicity parameter (EH) model of Petters and Kreidenweis (2007) and Kreidenweis et al. (2005, 2008), which is of the type:

$a_{\mathrm{w}}=\left(1+\kappa \frac{V_{\mathrm{s}}}{V_{\mathrm{w}}}\right)^{-1}$

$V_{\mathrm{s}}=n_{\mathrm{s}} M_{\mathrm{s}} / \rho_{\mathrm{s}}$ and $V_{\mathrm{w}}=n_{\mathrm{w}} M_{\mathrm{w}} / \rho_{\mathrm{w}}$ are the volumes $\left[\mathrm{m}^{3}\right]$ of the initially dry solute and pure water, respectively, with $M_{\mathrm{S}}$ and $M_{\mathrm{W}}\left[\mathrm{kg} \mathrm{mol}^{-1}\right]$ the molar masses of solute and water, respectively, and $\rho_{\mathrm{s}}$ and $\rho_{\mathrm{w}}\left[\mathrm{kg} \mathrm{m}^{-3}\right]$ the densities of the initially dry solute and pure water, respectively. The dimensionless hygroscopicity parameter $\kappa[-]$ parameterizes the composition dependent water activity of a solution droplet in analogy to the original van't Hoff factor. $\kappa$ and the van't Hoff factor $i_{\mathrm{s}}$ are related by:

$\kappa=i_{\mathrm{s}} \cdot \frac{n_{\mathrm{s}} \cdot V_{\mathrm{w}}}{n_{\mathrm{w}} \cdot V_{\mathrm{s}}}=i_{\mathrm{s}} \cdot \frac{v_{\mathrm{w}}}{v_{\mathrm{s}}}=i_{\mathrm{s}} \cdot \frac{\rho_{\mathrm{s}} \cdot M_{\mathrm{w}}}{\rho_{\mathrm{w}} \cdot M_{\mathrm{s}}}$

with $v_{\mathrm{s}}$ and $v_{\mathrm{w}}\left[\mathrm{mol} \mathrm{m}^{-3}\right]$ the molar volumes of the solute and of water, respectively. 
5. The universal functional group activity coefficient model (UNIFAC, Fredenslund et al., 1975), which describes the water activity by

$a_{\mathrm{w}}=f_{\mathrm{w}} \cdot x_{\mathrm{w}}=f_{\mathrm{w}} \cdot\left(1+M_{\mathrm{w}} \cdot \mu_{\mathrm{s}}\right)^{-1}$

$f_{\mathrm{w}}[-]$ denotes the rational or mole fraction scale activity coefficient of water, which is included in this $a_{\mathrm{w}}$ representation model to account for non-ideal solutions and solutes that dissociate (partly or completely). $x_{\mathrm{w}}$ [-] is the mole fraction of water in the solution that at equilibrium contains the numbers of moles (amount-ofsubstance) $n_{\mathrm{w}}$ and $n_{\mathrm{s}}$ [mol] of water and solute, respectively. $x_{\mathrm{w}}$ can be mathematically described as:

$x_{\mathrm{w}}=\frac{n_{\mathrm{w}}}{n_{\mathrm{w}}+n_{\mathrm{s}}}=\frac{1}{1+n_{\mathrm{s}} / n_{\mathrm{w}}}=\left(1+M_{\mathrm{w}} \cdot \mu_{\mathrm{s}}\right)^{-1}$

Analogously, the mole fraction of the solute $x_{\mathrm{s}}$ is given by

$x_{\mathrm{s}}=1-x_{\mathrm{w}}=\frac{n_{\mathrm{s}}}{n_{\mathrm{w}}+n_{\mathrm{s}}}=\frac{1}{1+n_{\mathrm{w}} / n_{\mathrm{s}}}=\left(1+\frac{1}{M_{\mathrm{w}} \cdot \mu_{\mathrm{s}}}\right)^{-1}$

i.e. satisfying the condition $x_{\mathrm{s}}+x_{\mathrm{w}}=1$ for a binary solution (sone solute and water).

$x_{\mathrm{w}}$ and $x_{\mathrm{s}}$ are related to the solute molality $\mu_{\mathrm{s}}$ [mol(solute) $\left.\mathrm{kg}^{-1}\left(\mathrm{H}_{2} \mathrm{O}\right)\right]$ by

$$
\begin{aligned}
\mu_{\mathrm{s}} & =\frac{n_{\mathrm{s}}}{m_{\mathrm{w}}}=\frac{n_{\mathrm{s}}}{n_{\mathrm{w}}} \cdot \frac{1}{M_{\mathrm{w}}}=\frac{x_{\mathrm{s}}}{x_{\mathrm{w}}} \cdot \frac{1}{M_{\mathrm{w}}}=\left(M_{\mathrm{w}} \cdot\left[1 / x_{\mathrm{s}}-1\right]\right)^{-1} \\
& =\left(M_{\mathrm{s}} \cdot\left[1 / \chi_{\mathrm{s}}-1\right]\right)^{-1}
\end{aligned}
$$

where $\chi_{\mathrm{s}}=\frac{m_{\mathrm{s}}}{\left(m_{\mathrm{s}}+m_{\mathrm{w}}\right)}[-]$ is the solute mass fraction, $m_{\mathrm{s}}$ and $m_{\mathrm{w}}[\mathrm{kg}]$ the masses of solute and water, with $M_{\mathrm{s}}$ and $M_{\mathrm{w}}\left[\mathrm{kg} \mathrm{mol}^{-1}\right]$ the corresponding molar masses, respectively.

To consider cases for which the solution contains more than one solute, Eqs. (A10a, b) are expressed in the more general form:

$x_{i}=n_{i} /\left(\sum_{j} n_{j}\right)$

$n_{i}$ is the number of moles [mol] of component $i$, where $i=w$ for the solvent, or $i=s$ for the solute; $j=$ $s_{1}, s_{2}, s_{3}, \ldots, s_{n}, w$ is the summation over all $n+1$ components in solution, so that $\sum_{j} x_{j}=1$.

Equation (A9) expressed in the general form yields the activity and the activity coefficient of solutes $(i=s)$ or the solvent water $(i=w)$, i.e.

$a_{i}=f_{i} \cdot x_{i}$ $f_{i}[-]$ is the rational activity coefficients and is defined on a reference state for which $f_{i}$ is unity for infinite dilution (pure water), so that $f_{i} \rightarrow 1$ as $x_{i} \rightarrow 0 . f_{i}$ of the solute $s$ is related to the molal-based activity coefficients $\gamma_{i}$ by (Robinson and Stokes, 1959):

$f_{i}=\gamma_{i}\left(1+M_{\mathrm{w}} \cdot \sum_{i} \mu_{i}\right)$

with the summation in Eq. (A14) over all solute molalities. $\left.M_{\mathrm{w}}\left[\mathrm{kg} \mathrm{mol}^{-1}\right)\right]$ is the molar mass of water, $\mu_{i}\left[\mathrm{~mol} \mathrm{~kg}^{-1}\left(\mathrm{H}_{2} \mathrm{O}\right)\right]$ the solute molality given by Eq. (A11).

The activity coefficients have been introduced to correct the solution molalities for non-ideality and to substitute earlier correction coefficients used in other $a_{\mathrm{w}}$ representations.

Rose08 have used the Pitzer-Simonson-Clegg mole fraction based model AIM of Clegg et al. (1998a, b), Wexler and Clegg (2002) as a reference model (Clegg and Wexler, 2007), which is based on osmotic coefficients, i.e. on Eq. (A4), and combines the OS model with the activity coefficient model, i.e. on Eqs. (A9-A14). Following Rose08, we have used in Sect. 3 the E-AIM model version III, which is available online (http://www.aim.env.uea.ac.uk/aim/model3/ mod3rhw.php) (Wexler and Clegg, 2002; Clegg and Wexler, 2007), as a reference to be consistent with the reference (AP3) of Rose08 (see their Table 3).

\section{Appendix B}

\section{B1 Determination of Eq. (1)}

Equation (1), introduced in Sect. 2.1, has been empirically derived with the following motivation: in Appendix A2 we have presented widely used water activity representations, including the Osmotic coefficient model (OS: Eq. A4), the Van't Hoff factor model (VH: Eq. A5), the Effective hygroscopicity parameter model (EH: Eq. A7), and the Activity coefficient model (AC: Eq. A9). A closer inspection of the numerics used by these models shows that they have the use of one class of fitting function type combined with a parameter in common, i.e. the $\mathrm{VH}, \mathrm{AC}$ and $\mathrm{EH}$ model use a rational function approach, whereas OS uses an exponential fit. The parameter itself is usually (with the exception of the EH-model) a multi parameter function that is more complex than the basic fitting function type. The basic idea behind our approach is to combine two types of fitting functions: a rational function, as used by the VH-model (Eq. A5) and an exponential function, as used by the OS-model.

A straightforward approach to do so, is:

$a_{\mathrm{w}}=\left(1+M_{\mathrm{w}} \cdot i_{\mathrm{s}} \cdot \mu_{\mathrm{s}}\right)^{-1}=\left(1+M_{\mathrm{w}} \cdot v_{i} \cdot \mu_{\mathrm{s}}^{\mathrm{o}} \cdot \exp \left(v_{i} \frac{\mu_{\mathrm{s}}}{\mu_{\mathrm{s}}^{\mathrm{o}}}\right)\right)^{-1}$ 
In Eq. (B1) we have introduced $v_{i}$ as the new single parameter and the constant $\mu_{\mathrm{s}}^{\mathrm{o}}=1\left[\mathrm{~mol} \mathrm{~kg}^{-1}\right]$ to correct for the units. Numerically this is simply a combination of two types of functional fits, physically this means that the molality $\mu_{\mathrm{s}}$ is now replaced by two factors: $\mu_{\mathrm{s}}^{\mathrm{o}} \cdot \exp \left(v_{i} \frac{\mu_{\mathrm{s}}}{\mu_{\mathrm{s}}^{\mathrm{o}}}\right)$, a constant and an exponential term. Is this the approach that should be used? Any water activity representation has to fulfill the following criteria for the limit of a dilute solution:

$$
\left(\lim _{\mu_{\mathrm{s}} \rightarrow 0} a_{\mathrm{w}}=1\right)
$$

which is clearly not the case for this approach:

$$
\begin{aligned}
& \left(\lim _{\mu_{\mathrm{s}} \rightarrow 0}\left(1+M_{\mathrm{w}} \cdot v_{i} \cdot \mu_{\mathrm{s}}^{\mathrm{o}} \cdot \exp \left(v_{i} \frac{\mu_{\mathrm{s}}}{\mu_{\mathrm{s}}^{\mathrm{o}}}\right)\right)^{-1}\right. \\
& \left.=\left(1+M_{\mathrm{w}} \cdot v_{i} \cdot \mu_{\mathrm{s}}^{\mathrm{o}}\right)^{-1}\right)
\end{aligned}
$$

A slight modification in the exponential term, the change towards a logarithmic dependence, will give the right result for the dilute solution limit.

$$
\begin{aligned}
a_{\mathrm{w}} & =\left(1+M_{\mathrm{w}} \cdot v_{i} \cdot \mu_{\mathrm{s}}^{\mathrm{o}} \cdot \exp \left(v_{i} \ln \left(\frac{\mu_{\mathrm{s}}}{\mu_{\mathrm{s}}^{\mathrm{o}}}\right)\right)\right)^{-1} \\
& =\left(1+M_{\mathrm{w}} \cdot v_{i} \cdot \mu_{\mathrm{s}}^{\mathrm{o}} \cdot\left(\frac{\mu_{\mathrm{s}}}{\mu_{\mathrm{s}}^{\mathrm{o}}}\right)^{v_{i}}\right)^{-1}
\end{aligned}
$$

Eq. (B3) equals Eq. (1) with $A=1$ and $B=0$, i.e. Para4 in Table 1, which provides accurate results for the relative humidity range: $\mathrm{RHD}<\mathrm{RH}<95 \%$. This approach, which can be regarded as a modified van't Hoff factor model, provides the basic relation between $a_{\mathrm{w}}$ and $\mu_{\mathrm{s}}$ in our framework. The parameterization models (1-2) and (3) of Table 1 are extensions of this fundamental equation. Additionally, this basic relation also sheds some light on the physical interpretation of the new parameter $v_{i}$. Similar to the van't Hoff factor $i_{\mathrm{s}}$, $v_{i}$ can be interpreted as a measure of solution non-idealities. Setting Eq. (A5) equal to Eq. (B3) reveals this aspect. Note that the van't Hoff-factor is often applied as a function of molality, e.g. a second order polynomial with three parameters (see Rose 08 for an overview), whereas our approach uses merely a single and constant parameter.

\section{B2 Determination of the correction terms $A$ and $B$ terms of Eq. (1)}

According to Fig. 2, our basic approach, Eq. (B3) represented by Para4, fails to represent the water activity beyond $0.95[-]$. Thus, the first straightforward approach has to be modified. The modifications have been chosen so that the fundamental structure of our fitting function is preserved: The numerator should be unchanged. The denominator should preserve its form, a sum with two addents. For simplicity the exponent of the second addent should not be modified. The modifications should be only functions of molality, but are allowed to include the parameter $v_{i}$. The modifications should not be allowed to dominate the basic mathematical characteristics of the original functional fit, i.e. the deviation from using $A=1$ and $B=0$ should be small (i.e. $A \approx 1$ and $B \ll \mu_{\mathrm{s}}$ ). Eq. (1), in the form of Para2, represents our choice, where the additional correction terms $A$ and $B$ are introduced:

$a_{\mathrm{w}}=\left(A+\mu_{\mathrm{s}}^{\mathrm{o}} \cdot M_{\mathrm{w}} \cdot v_{i} \cdot\left[\frac{1}{\mu_{\mathrm{s}}^{\mathrm{o}}} \cdot \mu_{\mathrm{s}}+B\right]^{\nu_{i}}\right)^{-1}$

with

$A=A_{v_{i}}\left(\mu_{\mathrm{s}}\right) ;\left(\lim _{\mu_{\mathrm{s}} \rightarrow 0} A=1\right)$

$B=B_{v_{i}}\left(\mu_{\mathrm{s}}\right) ;\left(\lim _{\mu_{\mathrm{s}} \rightarrow 0} B=0\right)$

and the dilution limit $a_{\mathrm{w}}=1$, which puts another constraint on the A and B-terms.

The functions we found for the A and B-terms are represented by Eqs. (2-3). These functions might seem complicated, but in fact are products of very basic functions. The A-term, Eq. (2), consists of two factors. The first one is simply a linear function in $\mu_{\mathrm{s}}, 1+M_{\mathrm{w}} \cdot v_{i} \cdot \mu_{\mathrm{s}}$, which equals 1 for $\mu_{\mathrm{s}}=0$. The second factor is of the well known Gaussian or bell curve type, which also equals 1 for a dilute solution. Since the bell curve is the dominant factor, the A-term could be interpreted as a bell curve with a slight linear correction. The first factor of the B-term, Eq. (3), is a basic rational function of the type $\frac{x}{1+x}$, which equals 0 for $\mu_{\mathrm{s}}=0$. During our numerical experiments we realized that this rational function converges too rapidly to 0 for small $\mu_{\mathrm{s}}$ and is too large for concentrated solutions. This has been corrected by the multiplication with a moderate root function. The pole at $\mu_{\mathrm{s}}=0$ of the root function is compensated by the fast conversion of the rational function term and the combined result gives 0 for $\mu_{\mathrm{s}}=0$. In practical applications the B-term has to be treated with some caution, i.e. very small molalities close to 0 have to be excluded. Additionally, numerical experiments revealed that in the range of RHD $<\mathrm{RH}<98 \%$ a B-term independent of molality can be obtained for $A=1$, i.e. $B=B_{98}$, given by Eq. (4), which provides accurate results. We included this parameterization model (labeled Para3 in Figs. 1-2), since it satisfies most aerosol applications in GCMs, i.e. those that do not intend to calculate $\mathrm{CCN}$ activation. Figures $7-8$ show the $A, B$ and $B$ 98-terms for the range $0<\mu_{\mathrm{s}}<\mu_{\mathrm{s}}{ }^{\text {sat }}$ for $\mathrm{NaCl}$ and illustrate the above arguments.

\section{B3 Determination of $v_{i}$ by solving Eq. (1) with a root-finding method}

According to the results shown by Figs. 1-6 in Sect. 3, we can assume $v_{i}$ constant for the entire range of water activity $a_{\mathrm{w}}(0-1)$. Therefore, we can determine $v_{i}$ for any single $a_{\mathrm{w}}-$ $\mu_{\mathrm{S}}$ data pair by solving Eq. (1) with a root-finding method. Since such a data pair is readily given at saturation, we use 
RHD and solubility measurements to constrain Eq. (5b). For each parameterization model of Table 1, we solve Eq. (5b), as outlined in Sect. 2.3, with the bisection method; see e.g. Numerical Recipes (http://www.nr.com/) in Fortran 90, Second Edition (1996), page 1185 (an online version is freely available at: http://apps.nrbook.com/fortran/index.html).

To determine the $v_{i}$ values listed in Table 2, we have used the following values for $\mathrm{NaCl}_{(\mathrm{cr})}$ and $\left(\mathrm{NH}_{4}\right)_{2} \mathrm{SO}_{4(\mathrm{cr})}$ at $T_{\mathrm{O}}=298.15[\mathrm{~K}]$ : mass fraction solubility $w_{\mathrm{s}}=0.2647[-]$ and $w_{\mathrm{s}}=0.4331[-]$, densities $\rho_{\mathrm{s}}=2170\left[\mathrm{~kg} \mathrm{~m}^{-3}\right]$ and $\rho_{\mathrm{s}}=1770\left[\mathrm{~kg} \mathrm{~m}^{-3}\right]$, relative humidity of deliquescence, $\mathrm{RHD}=0.7528[-] \mathrm{RHD}=0.7997[-]$, together with the molar masses $M_{\mathrm{S}}=0.05844\left[\mathrm{~kg} \mathrm{~mol}^{-1}\right]$ and $M_{\mathrm{S}}=$ $0.1321\left[\mathrm{~kg} \mathrm{~mol}^{-1}\right]$, respectively.

Note that a solution is quickly found for $v_{i}$ (usually much less than 20 iterations with the bisection method), since Eq. (5b)-RHD has, according to Figs. 9-10, a unique solution for each parameterization model of Table 1 . Also note that $v_{i}$ has to be determined only once from Eq. (5b) - RHD, but allows to solve Eq. (1) for the entire $a_{\mathrm{w}}$-range. The $v_{i}$ values of the solution Eq. (5b) - RHD $=0$ of Figs. 9-10 are shown in Table 2 for the four parameterization models. Although they differ, the distinction is small. $v_{i}$ can be determined for various compounds that are important for atmospheric aerosol modeling. The extension of $v_{i}$ to other compounds will be the focus of a companion paper (Metzger et al., 2011).

\section{Supplementary material related to this article is available online at: http://www.atmos-chem-phys.net/12/ 5429/2012/acp-12-5429-2012-supplement.zip.}

Acknowledgements. This work was partly supported by the CIRCE Integrated Project - Climate Change and Impact Research: the Mediterranean Environment (http://www.circeproject.eu/) and by the European Commission's Sixth Framework Program, Sustainable Development, Global Change and Ecosystems, Project No. 036961. The research leading to these results has received funding from the European Research Council under the European Union's Seventh Framework Programme (FP7/2007-2013)/ERC grant agreement no. 226144. We thank all contributors to discussions of this work, including those of Metzger and Lelieveld (2007) (http://www.atmos-chem-phys.net/7/3163/2007/acp-7-3163-2007. html), Xu et al. (2009) (http://www.atmos-chem-phys-discuss. net/9/9551/2009/acpd-9-9551-2009.html), Metzger et al. (2010) (http://www.atmos-chem-phys-discuss.net/10/ 8165/2010/acpd-10-8165-2010.html), Metzger et al. (2011) (http://www.geosci-model-dev-discuss.net/4/2791/2011/ gmdd-4-2791-2011.html).

The service charges for this open access publication have been covered by the Max Planck Society.

Edited by: M. Dameris

\section{References}

Biskos, G., Paulsen, D., Russell, L. M., Buseck, P. R., and Martin, S. T.: Prompt deliquescence and efflorescence of aerosol nanoparticles, Atmos. Chem. Phys., 6, 4633-4642, doi:10.5194/acp-64633-2006, 2006a.

Biskos, G., Russell, L. M., Buseck, P. R., and Martin, S. T.: Nanosize effect on the hygroscopic growth factor of aerosol particles, Geophys. Res. Lett., 33, L07801, doi:10.1029/2005GL025199, 2006 b.

Brechtel, F. J. and Kreidenweis, S. M.: Predicting Particle Critical Supersaturation from Hygroscopic Growth Measurements in the Humidified TDMA. Part I: Theory and Sensitivity Studies, J. Atmos. Sci., 57, 1854-1871, 2000.

Charlson, R. J., Schwartz, S. E., Hales, J. M., Cess, R. D., Coakley, J. A., Jr., Hansen, J. E., and Hofmann D. J.: Climate forcing of anthropogenic aerosols, Science, 255, 423-430, 1992.

Charlson, R. J., Seinfeld, J. H., Nenes, A., Kulmala, M., Laaksonen, A., and Facchini, M. C.: Reshaping the theory of cloud formation, Science, 292, 2025-2026, 2001.

Clegg, S. L., Brimblecombe, P., and Wexler, A. S.: A thermodynamic model of the system $\mathrm{H}^{+}-\mathrm{NH}_{4}^{+}-\mathrm{SO}_{4}^{2-}-\mathrm{NO}_{3}^{-}-\mathrm{H}_{2} \mathrm{O}$ at tropospheric temperatures, J. Phys. Chem. A, 102, 2137-2154, 1998a.

Clegg, S. L., Brimblecombe, P., and Wexler, A. S.: A thermodynamic model of the system $\mathrm{H}^{+}-\mathrm{NH}_{4}^{+}-\mathrm{Na}^{+}-\mathrm{SO}_{4}^{2-}-\mathrm{NO}^{-}-\mathrm{Cl}^{-}-\mathrm{H}_{2} \mathrm{O}$ at $298.15 \mathrm{~K}$, J. Phys. Chem. A, 102, 2155-2171, 1998b.

Clegg, S. L., Seinfeld, J. H., and Brimblecombe, P.: Thermodynamic modelling of aqueous aerosols containing electrolytes and dissolved organic compounds, J. Aer. Sci., 32, 713-738, 2001.

Clegg, S. L. and Wexler, A. S.: Interactive comment on "Calibration and measurement uncertainties of a continuous-flow cloud condensation nuclei counter (DMT-CCNC): CCN activation of ammonium sulfate and sodium chloride aerosol particles in theory and experiment" by Rose, D., Gunthe, S. S., Mikhailov, E., Frank, G. P., Dusek, U., Andreae, M. O., and Pöschl, Atmos. Chem. Phys. Discuss., 7, S4180-S4183, 2007.

Chemical Rubber Company (CRC): Handbook of Chemistry and Physics, 86th Edition, Taylor and Francis Group LLC, 20042005, CD-ROM version, 2006.

Dusek, U., Frank, G. P., Hildebrandt, L., Curtius, J., Schneider, J., Walter, S., Chand, D., Drewnick, F., Hings, S., Jung, D., Borrmann, S., and Andreae, M. O.: Size Matters More Than Chemistry for Cloud-Nucleating Ability of Aerosol Particles, Science, 312, 1375-1378, 2006.

Fountoukis, C. and Nenes, A.: ISORROPIA II: a computationally efficient thermodynamic equilibrium model for $\mathrm{K}^{+}$. $\mathrm{Ca}^{2+}{ }_{-} \mathrm{Mg}^{2+}-\mathrm{NH}_{4}^{+}-\mathrm{Na}^{+}-\mathrm{SO}_{4}^{2-}-\mathrm{NO}_{3}^{-}-\mathrm{Cl}^{-}-\mathrm{H}_{2} \mathrm{O}$ aerosols, Atmos. Chem. Phys., 7, 4639-4659, doi:10.5194/acp-7-4639-2007, 2007.

Frank, G. P., Dusek, U., and Andreae, M. O.: Technical note: A method for measuring size-resolved $\mathrm{CCN}$ in the atmosphere, Atmos. Chem. Phys. Discuss., 6, 4879-4895, doi:10.5194/acpd-64879-2006, 2006.

Frank, G. P., Dusek, U., and Andreae, M. O.: Technical Note: Characterization of a static thermal-gradient CCN counter, Atmos. Chem. Phys., 7, 3071-3080, doi:10.5194/acp-7-3071-2007, 2007. 
Fredenslund, A., Jones, R. L., and Prausnitz, J. M.: Group contribution estimation of activity coefficients in non-ideal liquid mixtures (UNIFAC), American Institute of Chemical Engineers Journal (AIChE. J.), 21, 1086-1099, 1975.

Hanford, K. L., Mitchem, L. Reid, J. P., Clegg, S. L., Topping, D. O., and McFiggans, G. B., Comparative Thermodynamic Studies of Aqueous Glutaric Acid, Ammonium Sulfate and Sodium Chloride Aerosol at High Humidity, J. Phys. Chem., 112, 94139422, 2008.

Harmon, C. W., Ronald L. Grimm, T. M. McIntire, M. D. Peterson, B. Njegic, V. M. Angel, A. Alshawa, J. S. Underwood, D. J. Tobias, R. B. Gerber, M. S. Gordon, J. C. Hemminger, and S. A. Nizkorodov, Hygroscopic Growth and Deliquescence of $\mathrm{NaCl}$ Nanoparticles Mixed with Surfactant SD, J. Phys. Chem. B, 114, 2435-2449, 2010.

IPCC: Climate Change 2007: The Physical Science Basis: Summary for Policymakers. Contribution of Working Group I to the Fourth Assessment Report of the Intergovernmental Panel on Climate Change, 2007.

Jacobson, M. Z.: Studying the effects of calcium and magnesium on size-distributed nitrate and ammonium with EQUISOLV II, Atmos. Environ., 33, 3635-3649, 1999.

Jacobson, M. Z., Tabazadeh, A., and Turco, R.: Simulating equilibrium within aerosols and non-equilibrium between gases and aerosols, J. Geophys. Res., 101, 9079-9091. 1996.

Konopka, P.: A re-examination of the derivation of the equilibrium supersaturation curve for soluble particles, J. Atmos. Sci., 53, 3157-3163, 1996.

Köhler, H.: The nucleus in and the growth of hygroscopic droplets, Trans. Faraday Soc., 32, 1152-1161, 1936.

Kreidenweis, S. M., Koehler, K., DeMott, P. J., Prenni, A. J., Carrico, C., and Ervens, B.: Water activity and activation diameters from hygroscopicity data - Part I: Theory and application to inorganic salts, Atmos. Chem. Phys., 5, 1357-1370, doi:10.5194/acp-5-1357-2005, 2005.

Kreidenweis, S. M., Petters, M. D., and DeMott, P. J., Single parameter estimates of aerosol water content, Environ. Res. Lett., 3, 035002, doi:10.1088/1748-9326/3/3/035002, 2008;

Künzli, N., Kaiser, R., Medina, S., Studnicka, M., Chanel, O., Filliger, P., Herry, M., Horak Jr., F., Puybonnieux-Texier, V., Quénel, P., Schneider, J., Seethaler, R., Vergnaud, J.-C., and Sommer, H.: Public-health impact of outdoor and traffic-related air pollution: a European assessment, The Lancet, 356, 795-801, 2000 .

Laaksonen, A., Korhonen, P., Kulmala, M., and Charlson, R. J., Modification of the Köhler equation to include soluble trace gases and slightly soluble substances, J. Atmos. Sci., 55, 853862, 1998.

Low, R. D. H.: A generalized equation for the solution effect in droplet growth, Atmos. Sci., 26, 608-611, 1969.

McFiggans, G., Artaxo, P., Baltensperger, U., Coe, H., Facchini, M. C., Feingold, G., Fuzzi, S., Gysel, M., Laaksonen, A., Lohmann, U., Mentel, T. F., Murphy, D. M., O'Dowd, C. D., Snider, J. R., and Weingartner, E.: The effect of physical and chemical aerosol properties on warm cloud droplet activation, Atmos. Chem. Phys., 6, 2593-2649, doi:10.5194/acp-6-2593-2006, 2006.

Metzger, S. and Lelieveld, J.: Reformulating atmospheric aerosol thermodynamics and hygroscopic growth into fog, haze and clouds, Atmos. Chem. Phys., 7, 3163-3193, doi:10.5194/acp-7-
3163-2007, 2007.

Metzger, S., Steil, B., Penner, J. E., Xu, L., and Lelieveld, J.: Derivation of the stoichiometric coefficient of water $\left(v_{\mathrm{w}}\right)$ to account for water uptake by atmospheric aerosols, Atmos. Chem. Phys. Discuss., 10, 8165-8188, doi:10.5194/acpd-10-8165-2010, 2010.

Metzger, S., Steil, B., Xu, L., Penner, J. E., and Lelieveld, J.: Description of EQSAM4: gas-liquid-solid partitioning model for global simulations, Geosci. Model Dev. Discuss., 4, 2791-2847, doi:10.5194/gmdd-4-2791-2011, 2011.

Mikhailov, E., Vlasenko, S., Niessner, R., and Pöschl, U.: Interaction of aerosol particles composed of protein and saltswith water vapor: hygroscopic growth and microstructural rearrangement, Atmos. Chem. Phys., 4, 323-350, doi:10.5194/acp-4-323-2004, 2004.

Mikhailov, E., Vlasenko, S., Martin, S. T., Koop, T., and Pöschl, U.: Amorphous and crystalline aerosol particles interacting with water vapor: conceptual framework and experimental evidence for restructuring, phase transitions and kinetic limitations, Atmos. Chem. Phys., 9, 9491-9522, doi:10.5194/acp-9-9491-2009, 2009.

Naono M. and Nakuman C.: Analysis of adsorption isotherms of water vapor for nonporous and porous adsorbents, J. Colloid Interface Sci., 145, 405-412, 1991.

Numerical Recipes (http://www.nr.com/) in Fortran 90, Second Edition, 1996.

Petters, M. D. and Kreidenweis, S. M.: A single parameter representation of hygroscopic growth and cloud condensation nucleus activity, Atmos. Chem. Phys., 7, 1961-1971, doi:10.5194/acp-71961-2007, 2007.

Pilinis, C., Pandis, S. N., and Seinfeld, J. H.: Sensitivity of direct climate forcing by atmospheric aerosols to aerosol size and composition, J. Geophys. Res., 100, 18739-18754, 1995.

Pitzer, K. S. and Mayorga, G.: Thermodynamics of electrolytes. II. Activity and osmotic coefficients for strong electrolytes with one or both ions univalent, J. Phys. Chem., 77, 2300-2308, 1973.

Pringle, K. J., Tost, H., Message, S., Steil, B., Giannadaki, D., Nenes, A., Fountoukis, C., Stier, P., Vignati, E., and Lelieveld, J.: Description and evaluation of GMXe: a new aerosol submodel for global simulations (v1), Geosci. Model Dev., 3, 391-412, doi:10.5194/gmd-3-391-2010, 2010.

Pruppacher, H. R. and Klett, J. D.: Microphysics of clouds and precipitation, Dordrecht, Kluwer Academic Publishers, 1997.

Raoult, F. M.: Über die Dampfdrucke ätherischer Lösungen, Z. Phys. Chem., 2, 353-373, 1888.

Reiss, H.: The kinetics of phase transitions in binary systems, J. Chem. Phys., 18, 840-848, 1950.

Robinson, R. A. and Stokes, R. H.: Electrolyte Solutions, (revised), London: Butterworth, 1959.

Robinson, R. A. and Stokes, R. H.: Electrolyte Solutions, 2nd ed. (revised); Butterworths: London, 1965.

Rose, D., Gunthe, S. S., Mikhailov, E., Frank, G. P., Dusek, U., Andreae, M. O., and Pöschl, U.: Calibration and measurement uncertainties of a continuous-flow cloud condensation nuclei counter (DMT-CCNC): CCN activation of ammonium sulfate and sodium chloride aerosol particles in theory and experiment, Atmos. Chem. Phys., 8, 1153-1179, doi:10.5194/acp-8-11532008, 2008.

Ruehl, C. R., Chuang, P. Y., and Nenes, A.: Aerosol hygroscopicity at high (99 to 100\%) relative humidities, Atmos. Chem. Phys., 
10, 1329-1344, doi:10.5194/acp-10-1329-2010, 2010.

Russell, L. M. and Ming, Y.: Deliquescence of small particles, J. Chem. Phys., 116, 311-321, 2002.

Seinfeld, J. H. and Pandis, S. N.: Atmospheric chemistry and physics, J. Wiley and Sons, Inc., New York, 1998.

Seinfeld, J. H. and Pandis, S. N.: Atmospheric chemistry and physics, J. Wiley and Sons, Inc., New York, 2006.

Stokes, R. H. and Robinson, R. A.: Interactions in aqueous nonelectrolyte solutions, I. Solute-solvent equilibria, J. Phys. Chem., 70, 2126-2130, 1966.

Shulman, M. L., Jacobson, M. C., Carlson, R. J., Synovec, R. E., and Young, T. E.: Dissolution behavior and surface tension ef-fects of organic compounds in nucleating cloud droplets, Geophys. Res. Lett., 23, 277-280, 1996.

Tang, I. N.: Chemical and size effects of hygroscopic aerosols on light scattering coefficients, J. Geophys. Res., 101, 1924519250, 1996.

Tang, I. N. and Munkelwitz, H. R.: Water activities, densities, and refractive indices of aqueous sulfates and sodium nitrate droplets of atmospheric importance, J. Geophys. Res., 99, 18801-18808, 1994.

van't Hoff, J. H.: Die Rolle des osmotischen Druckes in der Analogie zwischen Lösungen und Gasen, Z. Phys. Chem., 1, 481, 1887.

Wang, Z., King, S. M., Freney, E., Rosenoern, T., Smith, M. L., Chen, Q., Kuwata, M., Lewis, E. R., Pöschl, U., Wang, W., Buseck, P. R., and Martin S. T.: The Dynamic Shape Factor of Sodium Chloride Nanoparticles as Regulated by Drying Rate, Aerosol Sci. Technol., 44, 939-953, 2010.
Warneck, P.: Chemistry of the Natural Atmosphere, Internat, Geophys. Series, 41, Academic Press. Inc., 1988.

Wexler, A. S. and Clegg, S. L.: Atmospheric aerosol models for systems including the ions $\mathrm{H}^{+}, \mathrm{NH}_{4}^{+}, \mathrm{Na}^{+}, \mathrm{SO}_{4}^{2-}$, $\mathrm{NO}_{3}^{-}, \mathrm{Cl}^{-}, \mathrm{Br}^{-}$and $\mathrm{H}_{2} \mathrm{O}$, J. Geophys. Res., 107, 4207, doi:10.1029/2001JD000451, 2002.

Wexler, A. S. and Potukuchi, S.: Kinetics and Thermodynamics of Tropospheric Aerosols, Atmospheric Particles, John Wiley \& Sons Ltd., 1998.

Wexler, A. S. and Seinfeld, J. H.: Second-generation inorganic aerosol model, Atmos. Environ., 25A, 2731-2748, 1991.

Xu, L., Penner, J. E., Metzger, S., and Lelieveld, J.: A comparison of water uptake by aerosols using two thermodynamic models, Atmos. Chem. Phys. Discuss., 9, 9551-9595, doi:10.5194/acpd9-9551-2009, 2009.

Xu, L.: Global simulation of nitrate and ammonium aerosols and their radiative effects and comparison of satellite-based and modeled aerosol indirect forcing, Dissertation, University of Michigan, 2011.

Young, K. C. and Warren, A. J.: A reexamination of the derivation of the equilibrium supersaturation curve for soluble particles, J. Atmos. Sci., 49, 1138-1143, 1992.

Zdanovskii, A. B.: New methods of calculating solubilities of electrolytes in multicomponent systems, Zhu. Fiz. Khim., 22, 14751485, 1948. 